\section{Design and testing of a pulley and cable actuator for large ball valves}

\author{
L Pugi', E Galardi', G Pallini', L Paolucci' and N Lucchesi'
}

Proc IMechE Part I:

J Systems and Control Engineering

$\mathrm{I}-18$

(C) IMechE 2016

Reprints and permissions:

sagepub.co.uk/journalsPermissions.nav DOI: $10.1177 / 0959651816642093$

pii.sagepub.com

@SAGE

\begin{abstract}
The objective of this work is the development of an innovative actuator for Velan ABV S.p.A., which is mainly used for control and special on/off applications where high efficiency and linear behaviors are desirable specifications. The main performances of the proposed actuator, which has been protected by a patent, have been compared with a conventional scotch yoke one, using both the simulation results and the experimental data. In order to measure the efficiency and the dynamical response of the actuators, the authors have designed a hydraulic test rig, configured to fulfill different testing procedures. In this way, it is possible to perform both static tests to identify actuator efficiency and dynamic hardwarein-the-loop tests in which an assigned load or valve impedance function is simulated to verify the response of the tested object in realistic operating conditions. Finally, the proposed test rig has been successfully used to perform reliability and fatigue tests in which the actuator is stressed with realistic and repetitive loads. Moreover, the integrated development of both innovative actuator and testing devices is explained introducing interesting concepts whose applications are normally limited to robotics (e.g. impedance and force control) or vehicular technology (e.g. smart suspensions and suppression of vibrations).
\end{abstract}

\title{
Keywords
}

Pulley-cable actuator, quarter turn valve, hardware-in-the-loop testing, hydraulic servosystem, pneumatic servosystem, robust control

Date received: I0 April 2015; accepted: I March 2016

\section{Introduction}

The most common process valves used in oil and gas and petrochemical industries are quarter turn valves, mainly ball and butterfly, whose opening state is achievable with a $90^{\circ}$ rotation. These valves are usually controlled by single-acting pneumatic (or hydraulic) scotch yoke actuators, as shown in Figure 1.

However, nonlinear behavior and high sensitivity to internal friction on joints are the main drawbacks of the scotch yoke transmission, which should penalize the use of these actuators for applications that involve an accurate position control of the valve.

To solve these known drawbacks, different fluid rotary actuators have been studied: most of the documentation available in the literature is referred to patents concerning industrial applications, ${ }^{1-13}$ in which different gearings and articulated systems are proposed. However, most of these solutions have obtained a poor success in replacing the scotch yoke transmission. This is explained by the robustness and relative simplicity of the scotch yoke solution, which is fundamental for applications involving high reliability and safety levels.
Therefore, in this article, the authors present an innovative pulley and cable actuator for large ball valves. First, the main features of the scotch yoke transmission are discussed. Then, the design procedure using the LMS Amesim ${ }^{\mathrm{TM}}$ software is presented. To study the performances of the proposed actuator, the authors realized a suitable hardware-in-the-loop (HIL) test rig, whose design is described in a detailed way, considering both the design of the mechanical parts and the realization of a proper control system (realized in MATLABSimulink R2015a). Finally, several tests have been carried out through the test rig, which has been built in Capannori (Italy), in collaboration with ABV Velan S.p.A.

\footnotetext{
'Department of Industrial Engineering, University of Florence, Florence, Italy

${ }^{2}$ Velan ABV, S.p.A., Capannori, Italy

\section{Corresponding author:}

L Pugi, Department of Industrial Engineering, University of Florence, Via di S. Marta 3, 50139 Florence, Italy.

Email: luca.pugi@unifi.it
} 


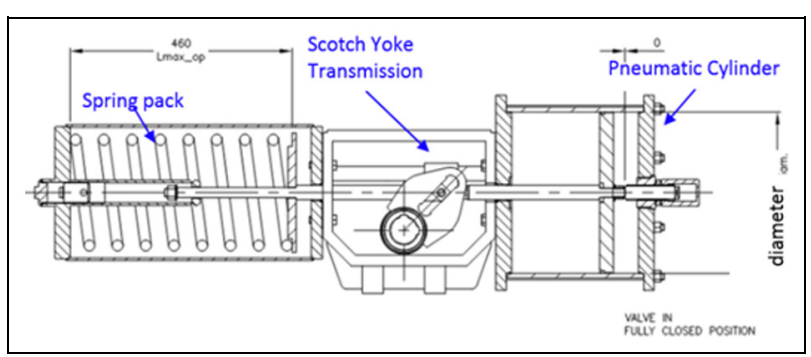

Figure I. Example of quarter turn valve actuation using a pneumatic cylinder and a scotch yoke transmission system.

\section{The scotch yoke actuator}

The scotch yoke transmission converts the linear motion of pneumatic cylinder into quarter turn rotation. The preloaded spring ensures the valve safety state when no pressure is provided to the actuator. If these valves are used for proportional control purposes, their rotation angles have to be regulated. The instrumental device normally used for this goal is called "positioner" and is composed of the following components:

- Angular position feedback: angular position and consequently the state of the valve are continuously measured.

- Regulator: typically, a proportional-integral-derivative (PID) position control is implemented.

- Valve or drive: according to a reference command produced by the regulator, a drive system, typically a 3/3 valve, is used to control the flow and, consequently, the pressure inside the actuator chamber depends on the value of the exerted torque.

The exerted torque $M_{i d}$ in ideal conditions (no friction losses on joints, $\rho=0$ ) can be calculated as a function of pressure $P$ inside the actuator and the angular position as shown in equation (1), which is referred to the simplified static scheme of Figure 2

$$
M_{i d}(\theta)=\frac{\left(P A-k\left(x-x_{0}\right)\right) b}{\cos \left(\theta-\frac{\pi}{4}\right)^{2}}
$$

where $A$ defines the actuator area, $b$ represents the distance between the revolute joint and cylinder axes, $k$ is the spring pack stiffness, $x$ and $x_{0}$ define, respectively, the spring position and preload, and $\theta$ is the valve angular position.

Figure 2 shows all the main forces applied to the mechanical assembly, and, in particular, it is possible to highlight the presence of a secondary reaction force $F_{2}$. The required prismatic constraint, which shares with the valve joint part of the component of $F_{1}$ on the orthogonal direction to $x$ (see Figure 2), prevents the thrust rod bending, but at the same time produces a new friction contribute that decreases the efficiency of the system.

The efficiency $\eta$ of the transmission system, considering the internal friction of both prismatic and revolute

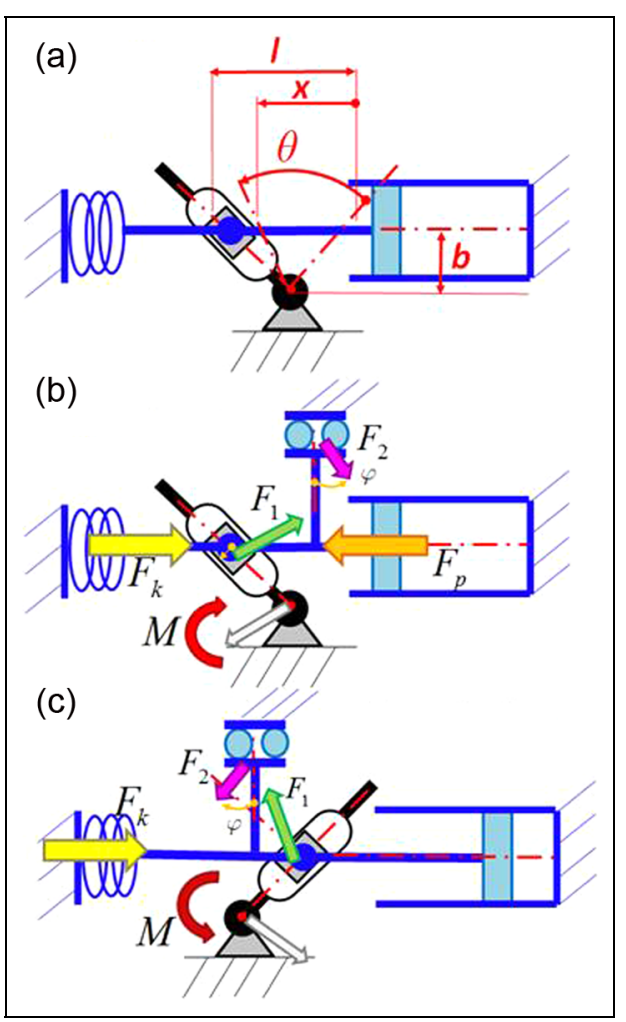

Figure 2. Simplified static scheme of the scotch yoke actuator: (a) simplified kinematic scheme and notation; exchanged forces (neglecting inertial forces) during (b) opening and (c) closing maneuvers of the actuator.

joints, can be easily evaluated using expressions (3), calculated using conventional graphical methods used to solve planar mechanical system 1

$$
\begin{gathered}
\eta=\frac{M}{M_{i d}}=\eta_{\text {prism }} \eta_{\text {rot }} \\
\eta_{\text {rot }}=\left(1-2 \frac{\rho}{r} \cos \left(\theta-\frac{\pi}{4}\right)\right) \\
\left|\theta-\frac{\pi}{4}\right| \geqslant \varphi \Rightarrow \eta_{\text {prism }}=\frac{1}{1+2 \mu \tan \left(\theta-\frac{\pi}{4}\right)-\mu^{2}} \\
\left|\theta-\frac{\pi}{4}\right|<\varphi \Rightarrow \eta_{\text {prism }}=\frac{1}{1+\mu^{2}}
\end{gathered}
$$

where $M$ defines the exerted torque, $\eta_{\text {prism }}$ and $\eta_{\text {rot }}$ are, respectively, the efficiencies of the prismatic and revolute joints, $\rho$ is the radius of the friction circle for the pulley bearings, $\mu$ and $\varphi$ are, respectively, the friction coefficient and angle, and $r$ is the radius of the pulley. From expressions (1) to (3), the main advantage and drawback of the scotch yoke transmission system are as follows:

- The actuator torque characteristic (torque vs angle position) fits well with the ball valve one, producing the same highest torque values, that is, near to the two valve end-runs $\left(\theta=0^{\circ}\right.$ and $\left.\theta=90^{\circ}\right)$. The typical behavior of the opening and closing torques of a ball valve is visible in Figure 3. The torque profiles 
Table I. Reference scotch yoke actuator (model PS2/S-A/I I0/C2) used for design and evaluation of the innovative prototype.

\begin{tabular}{llll}
\hline Cylinder diameter, $D$ & $0.28(\mathrm{~m})$ & Spring stiffness, $k$ & $51,500(\mathrm{~N} / \mathrm{m})$ \\
Spring preload, $x_{0}$ & $245(\mathrm{~mm}) 2620(\mathrm{~N})$ & Pressure, $P$ & $5(\mathrm{barG})$ \\
Distance, $b$ & $90(\mathrm{~mm})$ & Total run,, & $180(\mathrm{~mm})$ \\
\hline
\end{tabular}

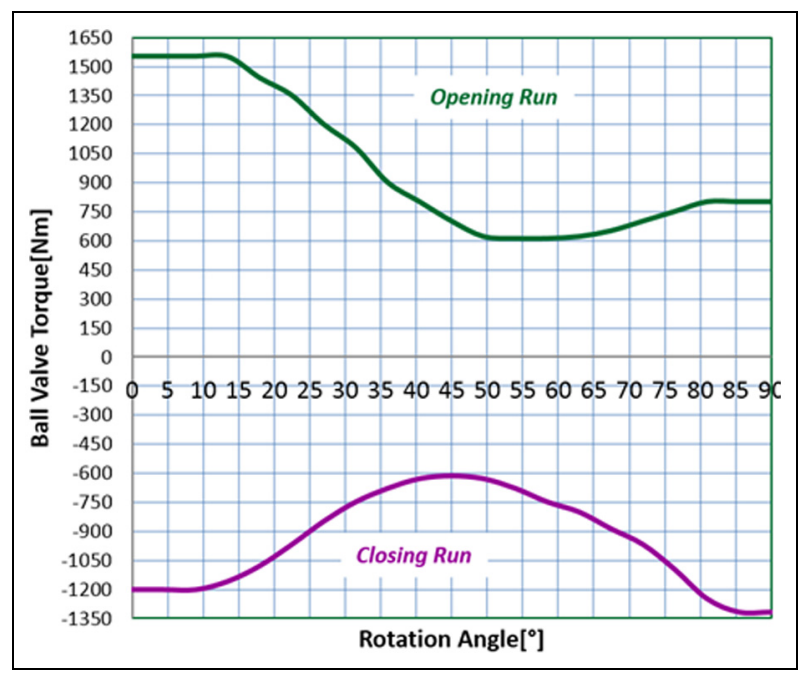

Figure 3. Typical torque profiles needed to open and to close a ball valve.

like the one described in Figure 3 can be measured on a pressurized valve using a customized actuator with an integrated torsiometer.

- The response of scotch yoke actuators is often negatively influenced by internal friction on joints, which drastically reduces efficiency, increases wear, and negatively affects precision and dynamic response of the system. In particular, high friction values make difficult the control of smooth motion profiles introducing hysteretic disturbances. A nonsecondary effect is the increase in wear on the joints and the corresponding loss of precision of the system.

\section{The proposed innovative actuator}

For the design of the innovative actuator, the authors considered the following specifications:

- The torque exerted by the proposed actuator at the end-runs $\left(\theta=0^{\circ}\right.$ and $\left.\theta=90^{\circ}\right)$ of the stroke should be almost equal to the ones produced by a reference scotch yoke solution.

- The efficiency of the proposed solution has to be higher with respect to the conventional scotch yoke transmission.

- The encumbrances of the proposed solution have to be at least similar to the existing scotch yoke system.

- The construction must be as simple as possible. In particular, the construction of the new actuator has

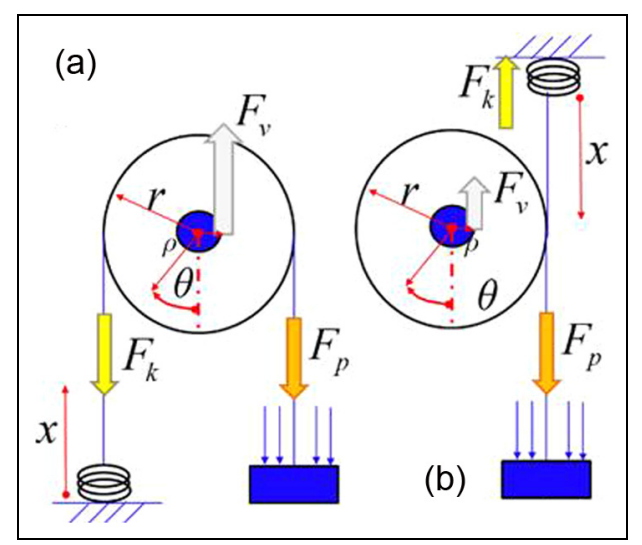

Figure 4. Simplified static models of the proposed actuator in (a) parallel and (b) aligned configurations during the opening phase.

to involve only the transmission system and not the pneumatic cylinder or the spring pack used to apply the preload, which should be equal or very similar to the reference one. In this way, it is possible to assure a high standardization and interchangeability of components of the actuators, built with both the conventional solution and the innovative one.

- Finally, the proposed solution has to be new and not covered by previous patents.

The proposed specifications involve the definition of a reference scotch yoke actuator to which the new solution should be compared. In particular, a standard product was chosen, whose main properties are visible in Table 1. The model PS2/S-A/110/C2 is considered because it is a standard ABV product. Moreover, it is an average size actuator, which could be employed for a wide range of process valves.

After a prolonged research, the authors adopted a very simple transmission system based on a pulley and cable system that is briefly described in the scheme of Figure 4. In all the kinematical configurations, a pulley is rotary activated by two tensioned cables, having one end fixed to the pulley and the other connected to the pneumatic actuator and the preload spring pack. The principle of operation is the same with respect to the scotch yoke solution visible in Figure 1 and, as required by specifications, it is possible to reuse the corresponding components (spring pack and pneumatic cylinder) employed for the conventional system. In addition, the adopted transmission system allows having different configurations in which the spring pack and the pneumatic cylinder have a different relative placement: 


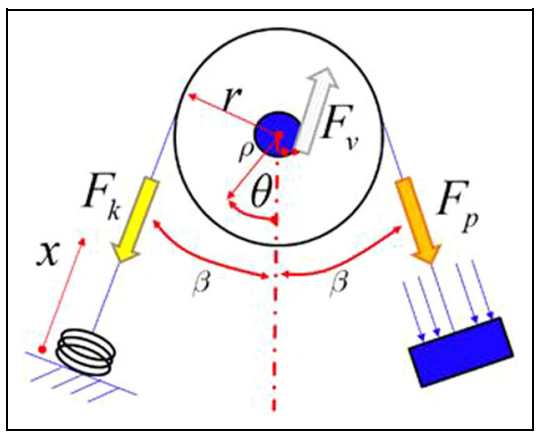

Figure 5. Simplified static models of the proposed actuator in the angular configuration.

- Parallel configuration: both spring pack and pneumatic actuators lay on the same side of the pulley casing.

- Aligned configuration: spring pack and pneumatic actuator are aligned so that the wires stretch in opposite directions.

- Angular configuration: the relative angular position of the spring pack with respect to the pneumatic actuator is described by an angle $\beta$, which is different from $0^{\circ}$ (parallel configuration) or $90^{\circ}$ (aligned configuration).

In Figures 4 and $5, F_{p}, F_{k}$, and $F_{v}$ define, respectively, the pneumatic actuator force, the spring force, and the reaction force on the revolute joint. The reference scotch yoke actuator (PS2/S-A/110/C2) is designed using almost the same pneumatic cylinder (same diameter and maximum operating pressures) and the same spring pack (same equivalent stiffness) adopted for the tested prototype of rotary actuator. In this way, the conventional and innovative actuators differ only in terms of the adopted mechanical transmission, making easier the comparison between different mechanical layouts.

Usually, one of the most important parameters to evaluate the efficiency of a pulley and cable system is the friction effect that guarantees the torque transmission 1 , even though many possible solutions exist (e.g. the use of chains and toothed belts). One of the possible alternatives to free the system from the dependency on the friction coefficient is to fix the cable on the pulley. The usage of a spring pack to preload the system is a specification, which requires a valve with a known mechanically assigned position in case of failure (loss of pressure of the fluid circuit).

The torque required by an electric actuation is very high (thousands of $\mathrm{Nm}$ ); therefore, a direct torque application is out of discussion. Consequently, the application of an electric actuator involves a gearbox and a transmission system. It should also be noticed that these valves are often used in large chemical or oil and gas plants, where fluid actuated actuators are often preferred for reliability or safety reasons.
Referring to the simplified static scheme of Figure 4, it is possible to calculate the corresponding torque exerted by the actuator, neglecting inertial forces and the internal friction losses of joints and cables (equation (4))

$$
M_{i d}(\theta)=r\left(P A-k\left(r \theta-x_{0}\right)\right)
$$

Using the same static scheme of Figure 4, the efficiencies of parallel (equation (5)) and aligned configurations (equation (6)) are

$$
\begin{aligned}
& \eta(\theta)=\frac{P A\left(r-\rho_{*}\right)-k\left(r \theta-x_{0}\right)\left(r+\rho_{*}\right)}{\left(P A-k\left(r \theta-x_{0}\right)\right) r} \\
& \eta(\theta)=\frac{\left(r-\rho_{*}\right)}{r}
\end{aligned}
$$

where $\rho_{*}$ represents the global radius of the friction circle. It should be noticed that the loss coefficient takes count of both the losses of pulley bearing and wires since it is defined according to equation (7)

$$
\rho_{*}=\rho+\delta
$$

This approach is followed since the internal friction and bending losses of each wire can be modeled introducing a dissipative torque, which is proportional to the rope tension according to a multiplicative coefficient $\delta$. For a generic angular configuration described in Figure 5, the expression of the efficiency is a bit more complicated (equation (8))

$$
\eta=\frac{F_{p}(r+\rho(\sin \beta-\cos \beta))-F_{k}(r+\rho(\sin \beta+\cos \beta))}{r\left(F_{p}-F_{k}\right)}
$$

where $F_{p}$ and $F_{k}$ are, respectively, the pneumatic actuator and spring forces while $\beta$ is the characteristic angle of the actuator.

The preload of the spring should negatively affect the efficiency. In particular, looking at the efficiency expressions of the scotch yoke (equation (2)), it is clearly noticeable that the efficiency is not affected by spring preload. For the innovative/proposed one, the way in which the spring preload influences the efficiency is strongly influenced by the value of the angle $\beta$. In particular, for a null value of $\beta$ (parallel configuration), the sensitivity of the efficiency with respect to spring preload is maximized.

\section{Design of the innovative actuator}

The sizing of the pulley and cable transmission system is mainly characterized by three constraints that have to be optimized:

- Exerted torque: the torque can be calculated using relation (4) which can be further corrected according to the efficiency evaluated in relation (8). The actuator is constrained to reproduce the same maximum opening and closing torques $\left(M_{B T O}, M_{B T C}\right)$ 


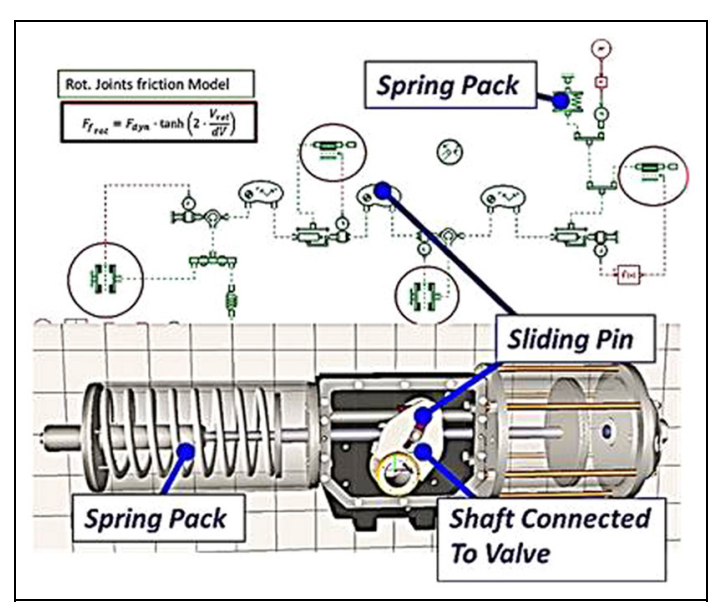

Figure 6. LMS Amesim model of the scotch yoke actuator.

of the reference scotch yoke actuator. If relation (4) is considered, the imposed constraints correspond to the system of equations (9)

$$
\begin{array}{r}
M(0)=M_{\text {ВТО }}=r\left(P A+k x_{0}\right) \\
M\left(\frac{\pi}{2}\right)=M_{\text {ВTC }}=-r k\left(r \frac{\pi}{2}-x_{0}\right)
\end{array}
$$

Since pressure $(P)$, stiffness of the spring pack $(k)$, and the torques $M_{B T O}$ and $M_{B T C}$ are assigned by specifications, the only parameters that can be iteratively modified are the radius of the pulley $r$ and the preload of the spring $x_{0}$. Since internal losses should affect the performances of the system, the calculation can be repeated considering system efficiency and admitting little variations in the other parameters, but this implies only slight adjustments of the system.

- Load acting on actuator wires: once system (9) has been solved, the load on each wire is almost known. It should also be considered that to avoid excessive bending stress on wires, the radius of the pulley has to be at least 20 times higher with respect to the rope one. Thus, the number of ropes and their diameter can be computed considering these two constraints.

During the design, the system was further improved using a numerical optimization procedure in LMS Amesim. In particular, a detailed model of both the conventional and the innovative (pulley and cable) actuators was developed: in both the multibody models, it is possible to introduce compliance and friction forces on every joint. The models can also be used for dynamic simulations since the pneumatic position loop of the positioner is modeled. A detail of the scotch yoke model is visible in Figure 6, and the comparison between the efficiency calculated by the multibody model and the theoretical one, calculated according to equation (3), is shown in Figure 7. It should be noticed that errors are

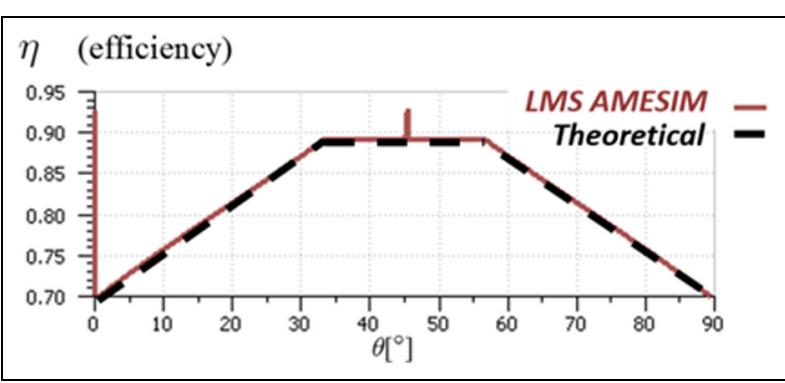

Figure 7. Comparison of efficiency calculation between LMS Amesim model of the scotch yoke and corresponding calculation using relation (3).

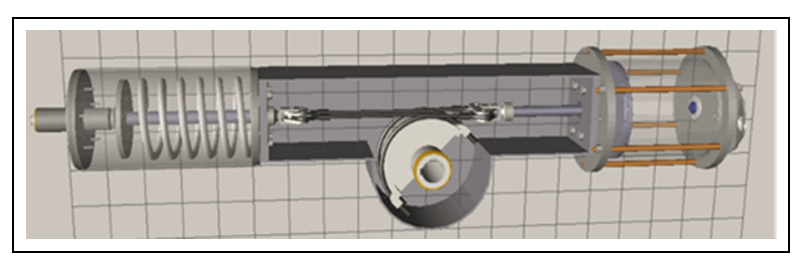

Figure 8. LMS Amesim model of the pulley and cable actuator $\left(\beta=90^{\circ}\right)$ in a preliminary design phase.

negligible except for the calculated value with an angular position of $45^{\circ}$. This error can be easily explained considering that for an angular position of $45^{\circ}$ the relative sliding of the prismatic pair of the oscillating connecting rod is instantaneously null. Friction models used in multibody models are based on the evaluation of the sign of relative sliding, so for the considered position this calculation is numerically critical. Also for a null rotation angle when the model is initialized, some additional errors on the calculated efficiency should be noticed.

The LMS model of the innovative actuator is shown in Figure 8. The geometry of the LMS model is parametric; hence, some features can be modified to fully optimize some additional parameters such as the angle $\beta$, thus minimizing the encumbrances of the proposed solution. This procedure is performed automatically using the internal optimization tool of the software, which allows to build simulation sequences with variable parameters and to iteratively optimize some assigned parameters in order to minimize a userdefined cost function. In particular, the authors defined an encumbrance function corresponding to the product of the squared values of length, width, and depth of the actuator. The minimization procedure was constrained considering the necessity to avoid the mutual interference of possible colliding parts such as the spring pack cylinder and the pneumatic one.

It is interesting to notice that at the end of the optimization procedure, an angular layout with an angle $\beta$ of about $14^{\circ}$ was preferred, as visible in Figure 9. 


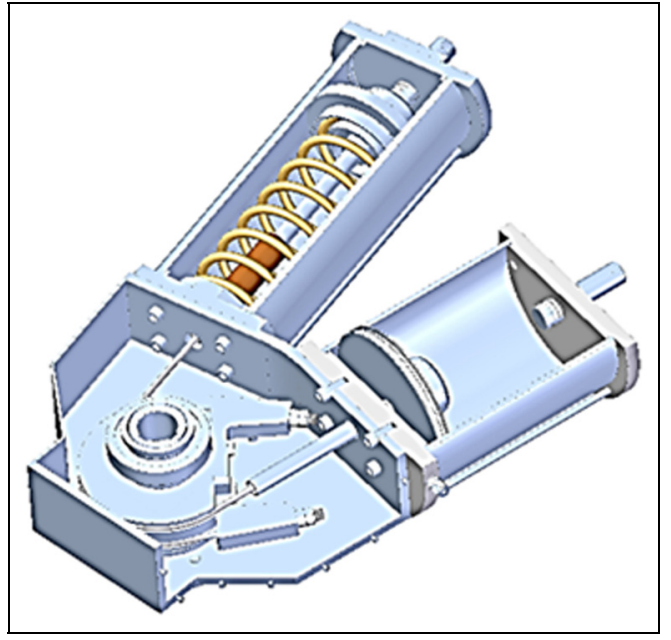

Figure 9. Pulley and cable actuator, optimized solution with minimized encumbrances.

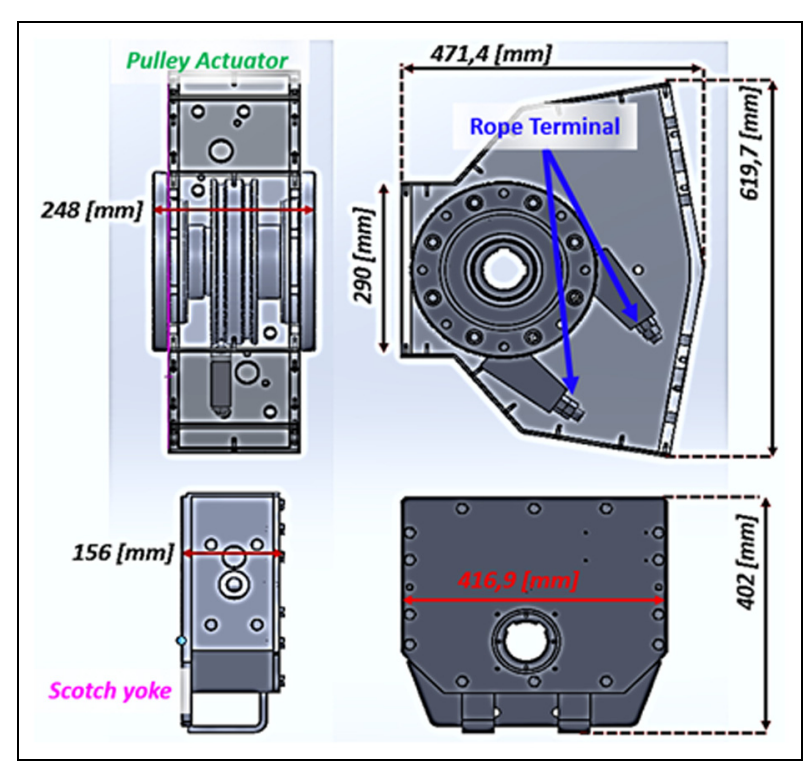

Figure 10. Comparison of encumbrances of the mechanical transmission between innovative actuator and scotch yoke.

A comparison between the encumbrances of the pulley transmission and the conventional one is visible in Figure 10. The result is quite encouraging considering that a further optimization of the actuator dimensions can be performed by improving the shape of rope terminals that are a bit oversized to improve their resistance to mechanical fatigue.

\section{Testing specifications}

The proposed innovative actuator and the corresponding reference one have been subjected to a comparative test campaign to evaluate their performances. Since the main features of the scotch yoke actuator are quite known (it is a stable industrial product, so data and references from field activities are available), it is also

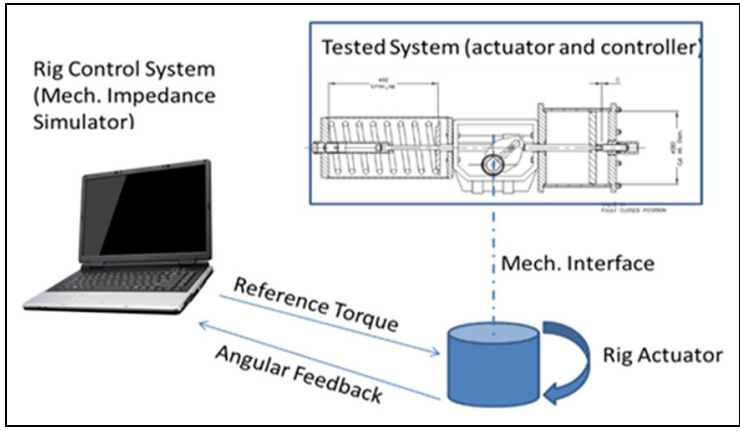

Figure I I. Principle of operation of the proposed test rig.

possible to verify the reliability of the proposed testing devices that were internally designed, built, and calibrated by the authors. In particular, both the actuators are subjected to the following tests:

- Actuator identification: a known constant supply pressure is applied to the actuator. The exerted torques and the corresponding angular positions of the actuators are measured. The aim of the test is to measure the real torque profile $M(P, \theta)$ and to identify the efficiency, $\eta(P, \theta)$, during both the opening run and closing run.

- Simulated load tests: as visible in the scheme of Figure 11, the actuator is controlled in position by its positioner. The actuator is mechanically connected to a device able to simulate a known mechanical load (resisting torque) as a function of the angular position of the actuator simulating the resisting torque of a virtual valve, which is not physically installed on the rig. In this way, this is a classic case of HIL simulation in which a mechatronic system is tested in a virtual environment able to reproduce real operating conditions. One of the novelties of this article is clearly represented by the application of the HIL approach to the energy industry, while they were generally applied only to robotic and vehicular system technologies.

- Reliability tests: simulated load tests are automatically repeated in order to reproduce a sequence of $1000-10,000$ load cycles. The aim of the test is to verify the reliability (absence of rupture or damage to any component) and repeatability of performances in real operating conditions.

\section{Actuator identification test}

\section{Design and layout of the test rig}

The test rig is designed in order to be used not only for the first prototype of the proposed actuator but also more generally to the wide range of different quarter turn actuators produced by Velan ABV SPA. Consequently, the specifications are quite demanding in terms of operating conditions (in Table 2). As visible 
Table 2. Specifications used for the design of the test rig.

\begin{tabular}{ll}
\hline Parameter & Min-medium-max values \\
\hline Angular run $\left({ }^{\circ}\right)$ & $80-90-100$ \\
Max. angular speed $(\mathrm{rad} / \mathrm{s})$ & $0.137-0.143-0.157$ \\
Max. acceleration $\left(\mathrm{rad} / \mathrm{s}^{2}\right)$ & $0.08-0.144-0.28$ \\
Max. resisting torque $(\mathrm{N} \mathrm{m})$ & $1000-50,000-10,000$ \\
Typical opening time $(\mathrm{s})$ & $5-10-20$ \\
Typical closing time $(\mathrm{s})$ & $5-10-20$ \\
\hline
\end{tabular}

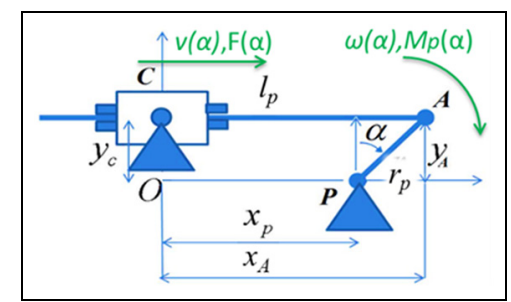

Figure I2. Kinematic scheme of the test rig hydraulic actuator.

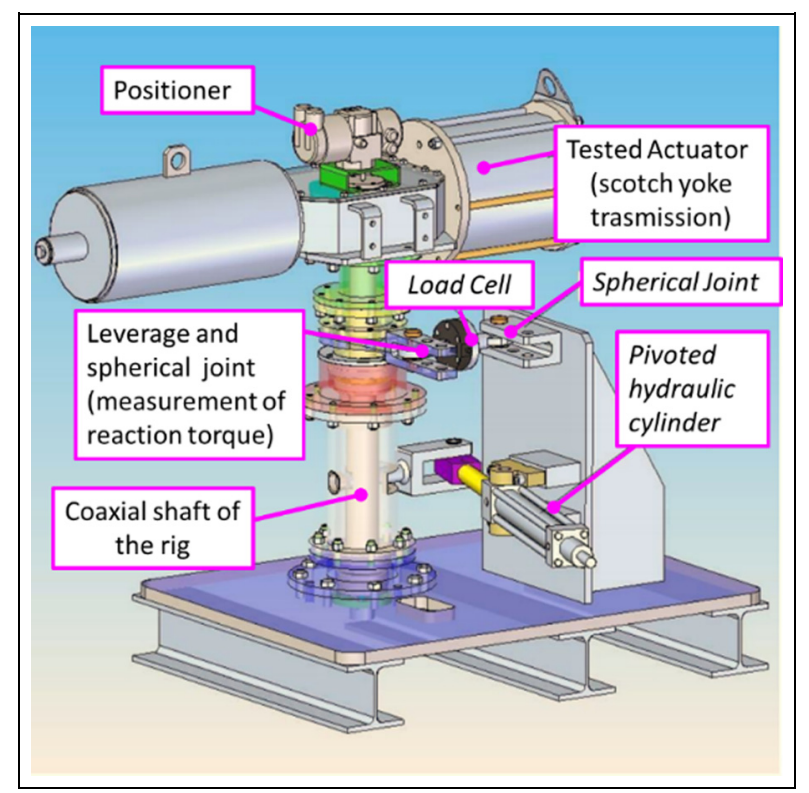

Figure 13. Main components of the test rig.

in Figure 13 and in the simplified scheme of Figure 12, the rig is composed of the following components:

- Tested quarter turn actuator: the tested actuator is charged with a known stable pneumatic pressure (opening phase) or discharged in atmosphere (closing phase). The actuator is directly connected to a shaft of the tested rig, which reproduces the typical mechanical interfaces adopted for valves.

- Hydraulic actuator and leverage: a pivoted doubleeffect, double-rod actuator is used to move a leverage in order to control the angular position of the shaft and consequently of the tested quarter turn actuator.
- Hydraulic position control loop: the hydraulic actuator of the rig is controlled using a $4 / 3$ proportional servo-valve feed with a maximum operating pressure of about $200 \mathrm{bar}$. A position controller is implemented on a dSPACE ${ }^{\circledR}$ DS 1411-1513 MicroAutoBox II board. The adopted algorithm is a simple proportional-integral (PI) regulator. Position feedback is assured by a high-resolution encoder (10,000 $\times 4$ divisions), which is calibrated using absolute linear position sensor on the rig actuator and rotational ones on the tested quarter turn actuator.

- Torque measurement: the actuator torque is measured in terms of reaction torque that has to be exerted in order to avoid the counter rotation of the actuator case. The reaction torque is measured using a traction-compression cell mounted on a leverage. This measurement technique is often used for the measurement of torque exerted by motors or brakes; in particular, the authors have adopted this solution from their previous experiences in design and certification of test rigs for railway braking systems. ${ }^{29}$

Hydraulic actuation has been preferred since it assures the possibility of exerting heavy torques with reduced encumbrances. Besides, it should be considered that the rig actuator has to be mostly regulated in order to work as a brake able to dissipate a continuously controlled power (the so-called second- and fourthquadrant operations). Management of electric drive is generally more complex in the braking phase; moreover, it is obvious to take into account penalties related to the limited quarter turn rotation and the impossibility of using gearings with high reduction ratio in order to reduce troubles related to friction, tooth backslash, and friction.

Commercial hydraulic torque motors are available in different sizes. However, considering cost specifications, a simple pivoted linear actuator linked to the rig (Figure 13) using the transmission system described in Figure 12 was preferred.

An important advantage of this solution is the opportunity to scale the project depending on the inputs: different solutions can be easily implemented to test bigger or smaller valves using commercial components. The main kinematic parameters of the transmission are described in Tables 2 and 3.

Figure 13 shows the mechanical assembly representing the test rig under evaluation. It is possible to recognize that the hydraulic cylinder, thanks to a lever, applies a torque to the inner shaft of the structure that directly transmits the torque to the actuator. Besides its structural role, the upper half of the outer shaft that is free to rotate (except for the load cell constraint) represents the path to read the reaction torque that constraints the scotch yoke to stay in position, which is equal to the torque transmitted by the actuator. 
Table 3. Main geometric parameters of transmission.

\begin{tabular}{lll}
\hline $\begin{array}{l}\text { Crank radius } \\
\text { of the rig }\end{array}$ & $\begin{array}{l}\text { Longitudinal distance } \\
\text { between cylinder pivot } \\
\text { and rig rotation axis }\end{array}$ & $\begin{array}{l}\text { Lateral distance } \\
\text { between } \\
\text { cylinder pivot and } \\
\text { rig rotation axis }\end{array}$ \\
\hline$r_{p}$ & $x_{p}$ & $\begin{array}{l}y_{c} \\
147 \mathrm{~mm}\end{array}$ \\
\hline
\end{tabular}

Table 4. Main parameters of the rig hydraulic actuator.

\begin{tabular}{lll}
\hline Parameter & Value & Notes \\
\hline $\begin{array}{l}\text { Internal diameter } \\
\text { Rod diameter }\end{array}$ & $\begin{array}{l}63 \mathrm{~mm} \\
45 \mathrm{~mm}\end{array}$ & $\begin{array}{l}\text { Corresponding area is about } \\
15 \mathrm{~cm}^{2}\end{array}$ \\
$\begin{array}{l}\text { Max. flow } \\
\text { Calculated for an augmented } \\
\text { max. speed of } 0.04-0.05 \mathrm{~m} / \mathrm{s}\end{array}$ \\
Pressure & $160-170$ bar & $\begin{array}{l}\text { To exert a torque of } 5000- \\
6000 \mathrm{~N} \mathrm{~m}\end{array}$ \\
\hline
\end{tabular}

The ratio $\tau(\alpha)$ between the exerted torque $M_{p}$ and the corresponding linear force of the hydraulic cylinder $F$ can be calculated according to equations (10)

$$
\begin{aligned}
\tau & =\frac{M_{p}}{F}=\frac{\dot{l}_{p}}{\dot{\theta}} \\
& =\frac{r_{p}\left(x_{p} \cos \alpha+y_{c} \sin \alpha\right)}{\sqrt{\left(\left(y_{c}-r_{p} \cos \alpha\right)^{2}+\left(x_{p}+r_{p} \sin \alpha\right)^{2}\right)}} \\
\alpha & =\theta-\frac{\pi}{4}
\end{aligned}
$$

where $\alpha$ defines the scaled angular position of the valve. In Figure 14, the transmission ratio $\tau(\alpha)$ scaled with respect to its value on the lower end-run $\tau(0)$ is represented. This behavior has been optimized since the opening torque of a simulated valve is typically slightly higher with respect to the closing one.

Considering the specifications and the kinematics of the rig, it is possible to size properly the hydraulic actuator, whose main data are visible in Table 4.

\section{Experimental results on the reference scotch yoke actuator}

The reference actuator was preliminary tested on the rig in order to obtain the following results:

- Reference performance: the efficiency of the reference actuator is measured with the same devices employed to evaluate the innovative one. Therefore, the comparison is more reliable.

- Preliminary verification of the testing device: since performances of the reference actuators are well known, it is possible to verify the functionality of the proposed testing device.

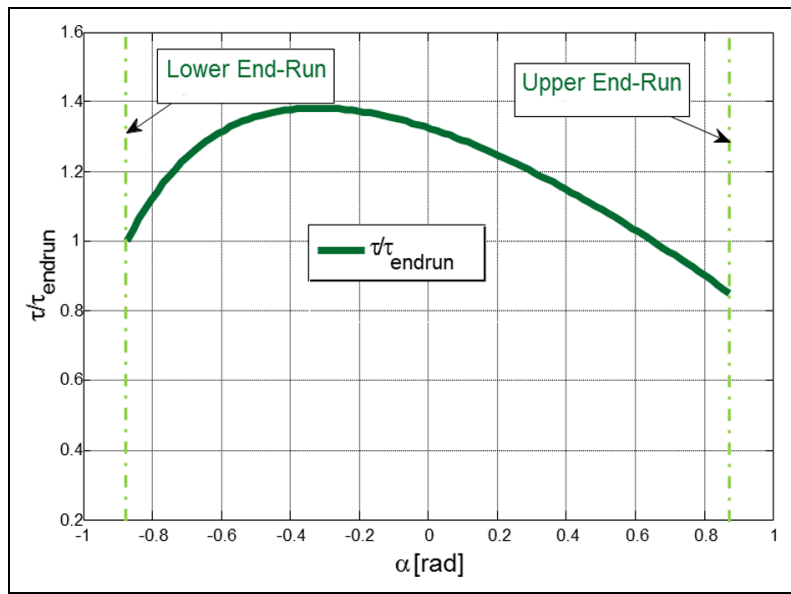

Figure 14. Behavior of the transmission ratio of the test rig with respect to its value on the lower end-run $\tau(0)$.

In Figure 15, the measured torque profiles during opening and closing phases are shown. The values are measured in static conditions (the actuator is not moving during a measurement during the acquisition of each point) to obtain a more stable measurement and reject inertial and static effects. It is clearly visible that the behavior of the actuator torque is similar to the ideal one calculated according to equation (1). The torque profiles of the actuators shown in Figure 15 are quite different from the corresponding valve loads of Figure 3. To explain this difference, it should be considered that in Figure 3 the loads that generally have to be exerted to open or close a ball/valve are represented (it does not follow to equation (1)). Equation (1) and Figure 15 are referred to torque profiles of scotch yoke actuators. The torques measured in Figure 15 have been obtained through the so-called position control of the rig, applying the following procedure: the tested actuator is fed with a constant pressure (opening phase) or pushed back by the spring preload (closing phase), while the angular position is imposed by the test rig using the action of the hydraulic servosystem. Moreover, to perform these tests, the position regulator of the positioner has to be disabled. The reduction in the exerted torque with respect to the ideal one is coherent with the calculated efficiency (equation (3)). In Figure 16, the measured efficiency of the actuator (estimated from the experimental data) is compared with the calculated values considering or neglecting the contribution of rotational joints.

The same testing procedure has been repeated on the proposed pulley and cable actuator with different pneumatic pressures from 5 to 6.5 bar. Some experimental results are shown in Figure 17. The experimental torque values are compared with the corresponding profiles calculated considering both ideal conditions (no losses on joints) and a constant equivalent friction radius $\rho$ of $3 \mathrm{~mm}$.

It is interesting to notice that the closing torque is not affected by the value of the feeding pressure: when 


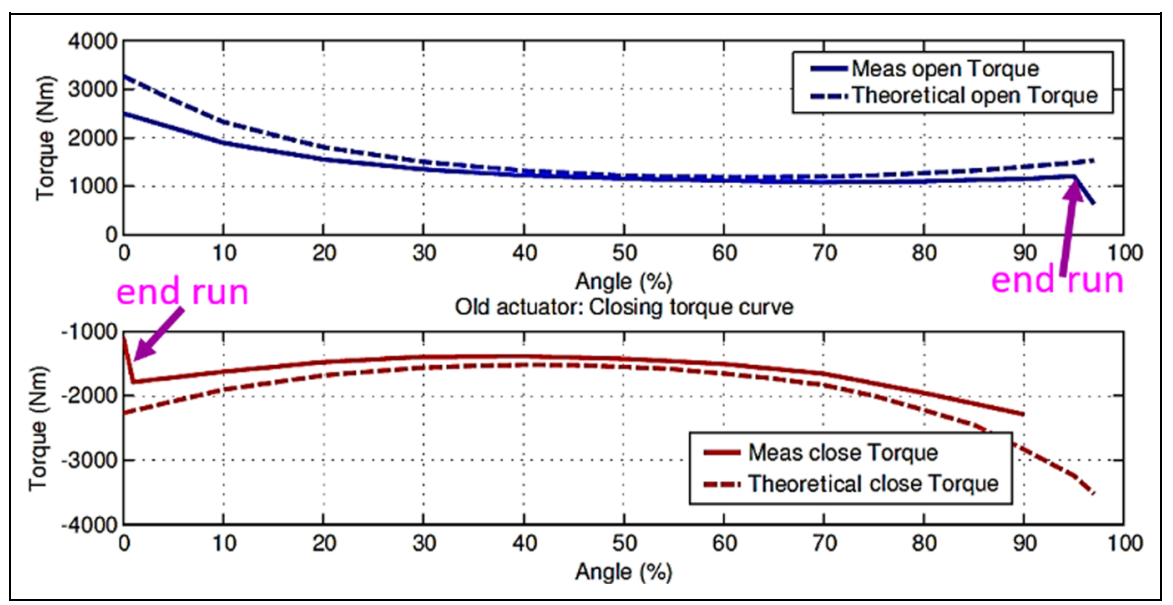

Figure 15. Measured torques in opening and closing runs with respect to opening percentage $\left(100 \%=90^{\circ}\right)$ and with respect to the ideal/theoretical torques, calculated considering a system with no losses on joints.

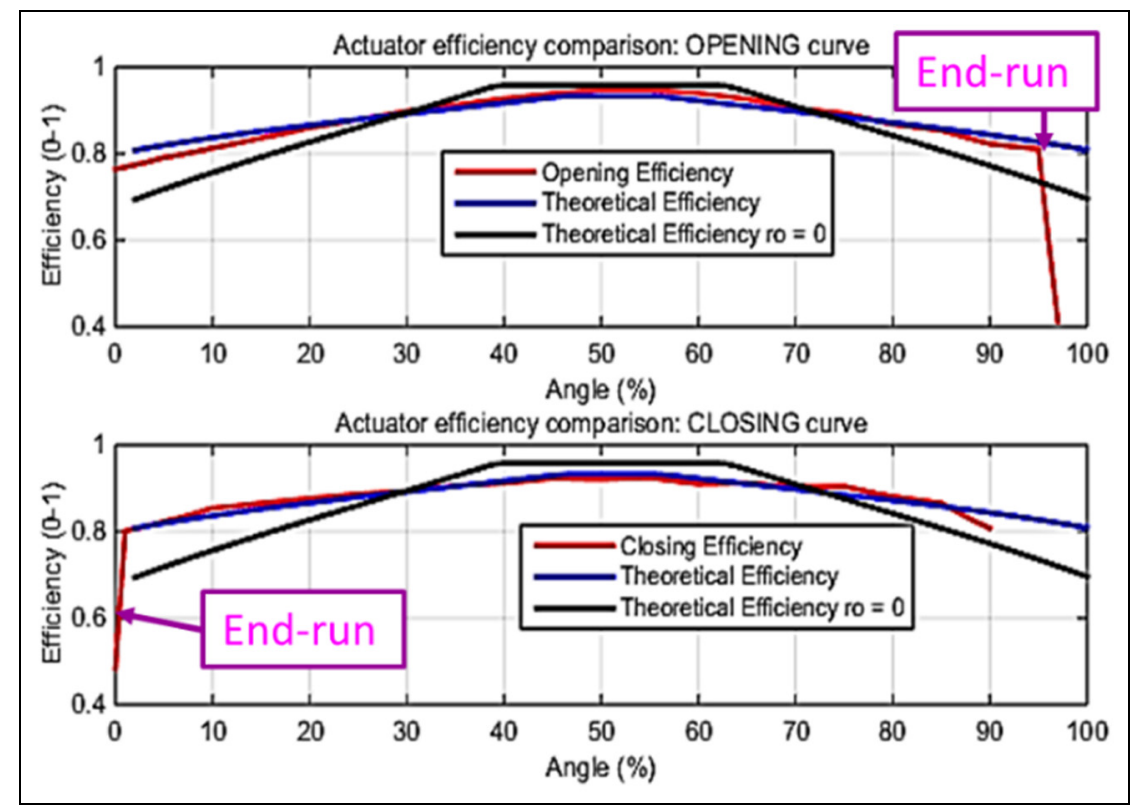

Figure 16. Measured efficiency in opening and closing runs with respect to opening percentage $\left(100 \%=90^{\circ}\right)$ with respect to the calculated efficiency considering loss on all joints or neglecting losses on rotoidal joints $(\rho=0)$.

the actuator closes the valve, the pneumatic cylinder is discharged so the steady-state torque delivered by the actuator in this phase depends only on the action of the spring pack. In particular, the measured efficiency of the pulley and cable actuator with respect to the conventional scotch yoke solution one is compared in Figure 18. The tests are performed in the same conditions (filling pressure of 5 bar). Moreover, the measured efficiency is compared with the theoretical one calculated according to equation (8). As clearly visible, there is a good agreement between the experimental data and the calculated one.

The innovative actuator has a much higher efficiency especially during the closing run. During the opening one, the conventional scotch yoke run has a slightly higher efficiency for intermediate angular positions around $45^{\circ}$. However, it should be noticed that the exerted torque of the innovative actuator in this intermediate positions is much higher with respect to the scotch yoke solution. In addition, the tested solution with $\beta$ equal to about $14^{\circ}$ has been chosen to reduce encumbrances; however, according to relation (8), adopting a $\beta$ angle equal to $90^{\circ}$ (aligned configuration), it is possible to obtain a much higher efficiency which can be quantified in about $98 \%$ (value calculated considering the same vale of friction loss radius $\rho$ ). Higher efficiency involves lower internal friction losses and consequently a better behavior for applications involving proportional control.

More generally as visible in Figure 17, the behavior of the exerted torque is much more linear, making easier the implementation of a controller. Finally, it 


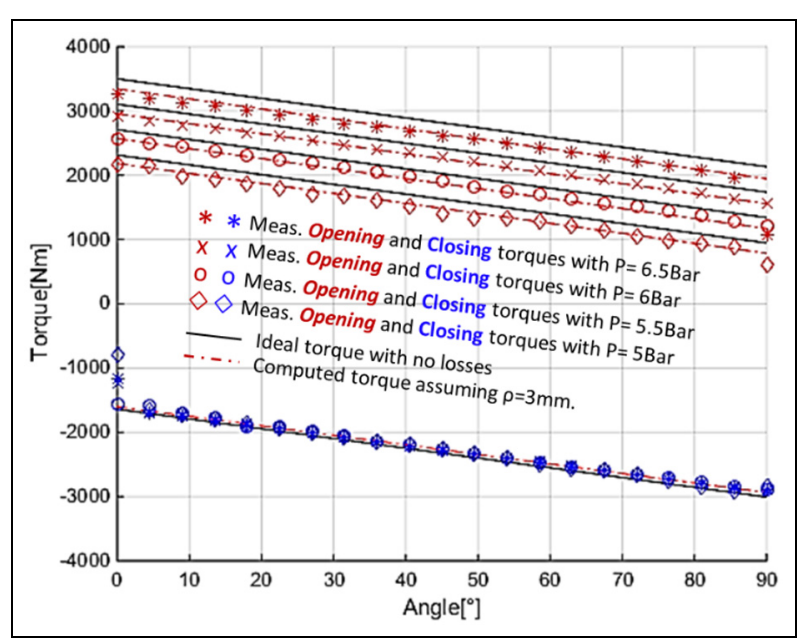

Figure 17. Measured torque values compared with the corresponding ideal one (no losses) and the theoretical ones calculated according to equation (8) and considering a constant equivalent friction radius $\rho$ of $3 \mathrm{~mm}$.

should be considered that, in the opening phase, different torques are measured with respect to different pneumatic pressures. The reason is due to the absence, in the closing phase, of the force generated by the variable pneumatic pressure that, conversely, is present in the opening phase.

\section{Simulated load tests}

\section{Design and layout of the test rig}

In order to apply a known simulated load to the tested actuator, the same test rig, described in Figure 11, has to be regulated in order to implement an accurate torque loop control. The interaction of the rig torque loop with a position-controlled system (the tested actuator) is potentially affected by stability troubles. In fact, the rig has to interact with a tested actuator whose dynamical behavior is unknown (the tested positioner has to be identified on the rig) and affected by uncertainties and nonlinearities. The problem of a robust simulation of mechanical impedance ${ }^{14}$ is quite common in robotics, where it is still the object of recent research works. In particular, this kind of solution is often studied for the development of compliant actuators ${ }^{15}$ for bio-inspired manipulators ${ }^{16}$ that have to deal with variable or uncertain operating conditions. ${ }^{17}$ Similar troubles have been studied also for the design of walking, legged robots. ${ }^{18}$ Moreover, the authors have specific experiences on this field, mostly derived from experimental activities on hydraulic active suspensions for a railway pantograph ${ }^{19,20}$ and from the design of hydraulic semi-active suspension systems of railway vehicles. ${ }^{21}$

The tested positioner has a quite slow dynamical response (valve opening time is about 10-12s), so a high dynamical response that should be granted by controlling pressure in both chambers ${ }^{22}$ of the hydraulic actuator of the rig does not represent a primary aim. In addition, the rig hydraulic cylinder has to be controlled in order to work as a hydraulic brake. These specifications arise from the following considerations:

- Emulated load: the emulated load is a resistive, dissipative torque of virtual-simulated ball valve. The tested positioners are tuned to produce a smooth, over-damped response, with no overshoot or residual oscillations.

- Stability and robustness: the rig is designed as a torque-controlled system that has to be coupled

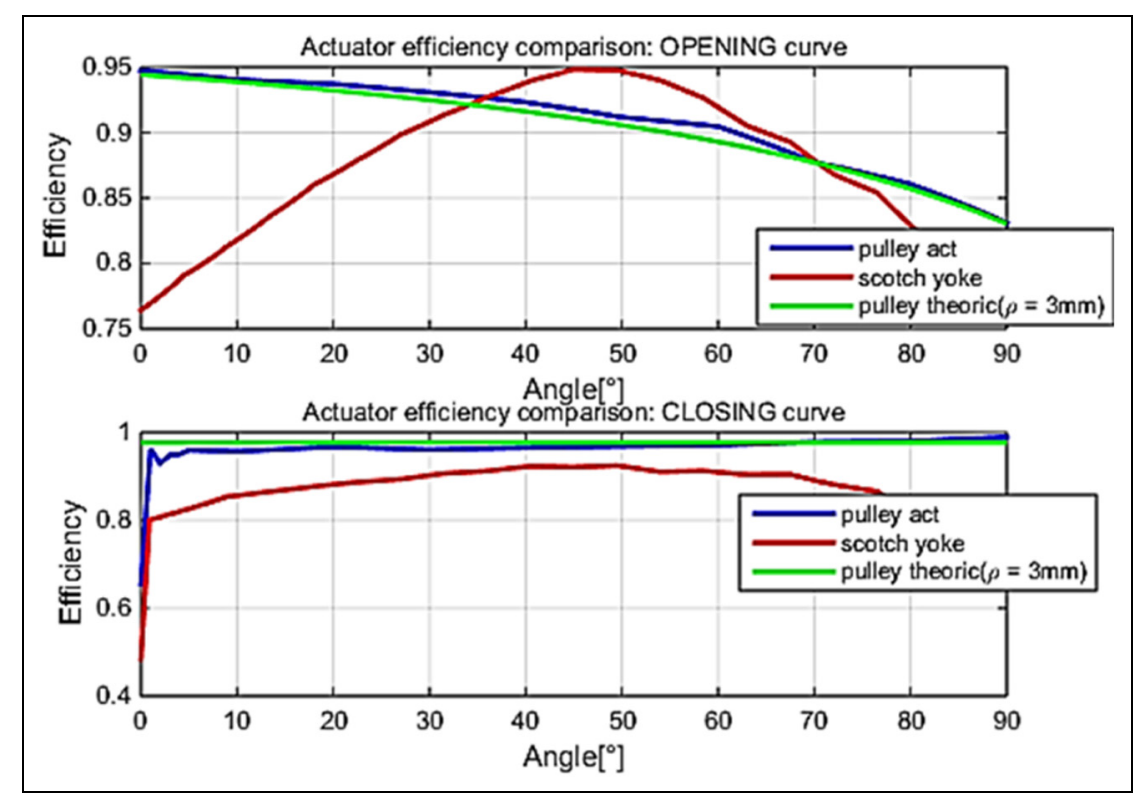

Figure 18. Comparison between the measured efficiency of the wire actuator with respect to the conventional scotch yoke solution one. 


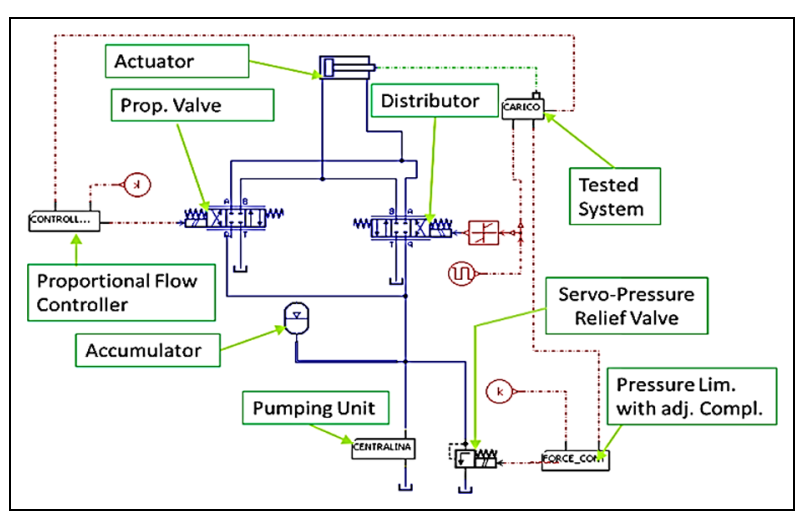

Figure 19. LMS Amesim model of complete hydraulic plant of the rig. ${ }^{23}$

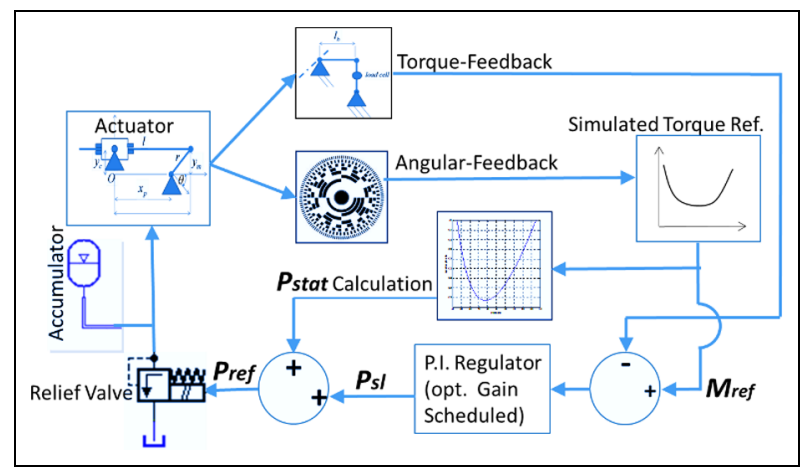

Figure 20. Simplified scheme of the hydraulic test rig including control logic during simulated load tests.

with a position-controlled one (tested actuator with positioner) whose main features in terms of dynamical response are quite uncertain and unknown since the tested system has to be calibrated or identified on the rig. Therefore, the controller of the rig has to be extremely robust with respect to the coupling with a poorly known position-controlled system.

- Irreversible behavior of the tested actuators: conventional scotch yoke transmissions have a very poor efficiency near both the end-runs. Therefore, their motion near the full opening $\left(\theta=90^{\circ}\right)$ and full closing position $\left(\theta=0^{\circ}\right)$ is irreversible. Consequently, an action of the hydraulic cylinder aiming to produce a reverse motion with respect to the active maneuver of the tested positioner may cause a potential dangerous overload.

In Figure 19, the LMS Amesim model of the complete hydraulic plant of the rig which has been object of a previous publication is shown: ${ }^{23}$ the same plant, according to the state of "distributor," "proportional valve," and "servo pressure relief valve," can be used to perform both identification and simulated load tests. In particular, when simulated load tests are performed, the proportional valve is closed and excluded from the circuit. Proportional valve is used to control the position of the hydraulic actuator during identification tests. Therefore, during simulated load tests, the plant is represented by the simplified scheme of Figure 20 .

The force and consequently the torque exerted by the rig hydraulic actuator are controlled by adjusting the pressure inside one of the two chambers, while the other one is discharged and connected to the tank.

According to the sign of the simulated load (valve opening or closing), the $4 / 3$ distributor visible in Figure 19 is configured to properly connect the cylinder to the plant.

The pressure is regulated using a servo-relief valve whose pressure reference is continuously controlled by an external reference voltage signal.

As visible in the scheme of Figure 20, the reference command pressure $P_{r e f}$ is calculated as the sum of two contributions:

- $P_{\text {stat }}$ : once the desired torque profile $M_{r e f}(\alpha)$ is calculated, the corresponding pressure $P_{\text {ref }}(\alpha)$ that the actuator has to reproduce should be computed according to equation (11), which is derived considering ideal static equilibrium of the machine (no friction, neglected inertial contributions, ideal hydraulic plant response)

$$
P_{\text {stat }}(\alpha)=\frac{M_{\text {ref }}(\alpha)}{\tau(\alpha)} \frac{1}{A}
$$

- $\quad P_{s l}: P_{s t a t}$ is calculated considering a simplified static model un-affected by disturbances. $P_{s l}$ is the contribution calculated by a closed-loop torque controller whose input is the error between the desired torque $M_{\text {ref }}$ and the measured one $M_{\text {feed }}$. The aim of the $P_{s l}$ contribution is to reject as much as possible unknown dynamics as a disturbance. This term is implemented as a PI controller saturated to a known value.

PI gains of the PI regulator are given (Table 5) for the torque control loop. In particular, considering the mean static value of $\tau$, it is also possible to calculate an approximate dimensionless gain between torque error and the corresponding correction torque exerted by the actuator.

The approach of the implemented controller resembles the philosophy of sliding mode controllers. ${ }^{24}$

In particular, considering an ideal static response of the rig, the $P_{\text {stat }}$ correction term corresponds to a null torque error of the control loop. Therefore, the system tends to converge to a null torque error with a dynamical response that is the result of the interaction between the torque loop of the rig and the tested positioner. Unfortunately, the dynamical response of the tested positioner is unknown, so the interaction with the rig should lead to a potentially unstable behavior. 
Table 5. Proportional and integral gain parameters.

\begin{tabular}{lllll}
\hline & Proportional gain, $K_{p}(\mathrm{bar} / \mathrm{N} \mathrm{m})$ & & Integral gain, $K_{i}(\mathrm{bar} / \mathrm{N} \mathrm{m})$ & Saturation on PI output \\
\cline { 2 - 2 } & $K_{p}$ mean $(\tau)$ & & $K_{i}$ mean $(\tau)$ & \\
\hline PI regulator_torque control & $0.024 \mathrm{bar} / \mathrm{N} \mathrm{m}$ & $0.024 \mathrm{bar} / \mathrm{N} \mathrm{m}$ & $20 \mathrm{bar}$ (max. plant pressure $=200 \mathrm{bar})$ \\
& 0.8 & 0.8 & \\
\hline
\end{tabular}

PI: proportional-integral.

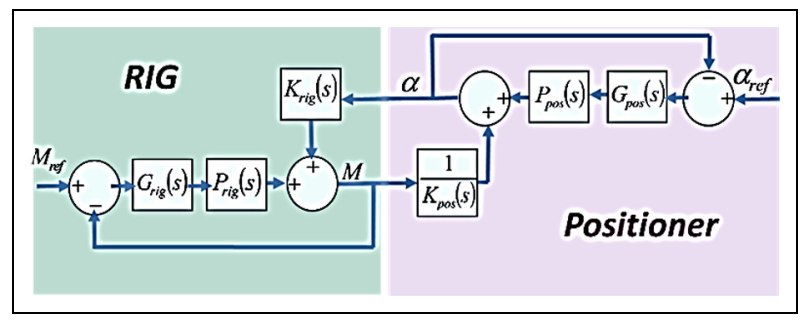

Figure 21. Simplified approach adopted to increase the robustness of the rig control and actuation system.

The proposed regulator is optimized in order to be very robust with respect to the disturbances introduced by the interaction with a potentially stiff tested positioner.

In order to make clearer the followed approach, the following simplified scheme is considered:

- The test rig is a treated as a torque-controlled system that has to reproduce the reference torque $M_{\text {ref }}$.

- The tested positioner is a position-controlled system able to follow a reference position $\alpha_{\text {ref }}$.

Both the interacting control systems have their own control loop (transfer functions $G_{p o s}(s)$ and $G_{r i g}(s)$ ) and actuation systems $\left(P_{\text {pos }}(s)\right.$ and $\left.P_{\text {rig }}(s)\right)$. The coupling between the dynamical behavior of the two systems is modeled considering the transfer functions $K_{p o s}(s)$ and $K_{\text {rig }}(s)$.

$K_{\text {pos }}(s)$ represents the equivalent stiffness of the tested positioner, which cannot be affected by the design of the rig. A low value of $K_{\text {pos }}(s)$ involves that the load $M$ negatively affects the precision of the positioner and this is a feature that can also be identified on the rig (Figure 21).

Since the dynamical response of the tested positioner is highly variable, in order to assure high levels of robustness, the authors optimized the rig transfer functions focusing on the rig equivalent stiffness $K_{r i g}(s)$. The module of $K_{\text {rig }}(s)$ has to be minimized in order to reduce potentially dangerous interactions between the two systems. This concept is quite common in hydraulic force-controlled systems such as in the works of Alleyne and $\mathrm{Liu}^{22}$ and Allotta et al. ${ }^{19}$

In particular, considering the plant layout of Figures 19 and 20, the dynamical behavior of the system is described by equation (12) in which the following simplifications are assumed to be valid:

- The pumping unit assures a constant flow $Q_{\text {pump }}$.

- The flow delivered to the controlled cylinder chamber is $Q$.

- The servo-relief valve flow $Q_{\text {valve }}$ is constrained to be negative since the valve should be used only to discharge the controlled capacities. For the sake of simplicity, the flow of the valve is supposed to be controlled by a proportional regulator with a constant gain $K$. Valve dynamics is reproduced as a second-order system with an eigen frequency $\omega_{n}$ of about $12 \mathrm{~Hz}$ and a damping coefficient of about 0.7-0.8. Technical information concerning valve response are taken from technical documentation of the valve maker. ${ }^{25}$ The same modeling approach is also commonly adopted by other well-known valve maker $^{26}$ and it is quite diffused in the literature ${ }^{27,28}$

$$
\begin{aligned}
Q & +Q_{\text {pump }}+Q_{\text {valve }}=K\left(P_{\text {ref }}-P\right) \frac{\omega_{n}^{2}}{s^{2}+2 \varepsilon \omega_{n} s+\omega_{n}^{2}} \\
& +Q_{\text {pump }}-\left(A x s+\frac{V_{0 *}}{E_{b *}} s P\right)=0 \\
& +Q_{\text {pump }}-\left(A x s+\frac{V_{0 *}}{E_{b *}} s P\right)=0
\end{aligned}
$$

In equation (12), the equivalent compressibility term $\left(V_{0^{*}} / E_{b^{*}}\right)$ is highly influenced by the presence of air or nitrogenum-filled accumulator. In particular, the compressibility of the pneumatic accumulator is largely dominant and should be approximately calculated according to equation (12)

$$
\frac{V_{0 *}}{E_{b *}}=\frac{d V}{d P} \approx \frac{V_{a c c}^{\gamma+1}}{\gamma\left(P_{\text {init }} V_{\text {init }}^{\gamma}\right)}
$$

where the following symbology is adopted:

- $\quad V_{a c c}$ is the current volume of the pneumatic accumulator, while $P_{\text {init }}$ and $V_{\text {init }}$ represent the initial (preload) pressure and volume values, respectively;

- $\quad \gamma$ is the coefficient of the polytropic transformation which is used to approximate the behavior of the gas in the accumulator.

Solving equation (12), it is possible to calculate the behavior of pressure $P$ of the controlled chamber of the actuator as a function of three inputs, $Q_{\text {pump }}, P_{\text {ref }}$, and $x$ 


$$
\begin{aligned}
P= & Q_{\text {pump }} \frac{1}{\left(\frac{K \omega_{n}^{2}}{s^{2}+2 \varepsilon \omega_{n} s+\omega_{n}^{2}}+\frac{V_{0 *}}{E_{b *}} s\right)} \\
& +P_{r e f} \frac{1}{\left(1+\frac{V_{0 *}}{K E_{b *}^{2}} s\left(s^{2}+2 \varepsilon \omega_{n} s+\omega_{n}^{2}\right)\right)} \\
& +x \frac{-A s}{\left(\frac{K \omega_{n}^{2}}{\left(s^{2}+2 \varepsilon \omega_{n} s+\omega_{n}^{2}\right)}+\frac{V_{0 *}}{E_{b *}} s\right)}
\end{aligned}
$$

Since the area of actuator $A$ and transmission ratio $\tau(\alpha)$ are known, it is possible to calculate from equation (14) the three transfer functions $G_{\text {pump }}(s), G_{r e f}(s)$, and $K_{\text {rig }}(s)$, between the three inputs $Q_{\text {pump }}, P_{\text {ref }}$, and $x$ and the torque $M$ delivered by actuator (15)

$$
\begin{aligned}
M & =Q_{\text {pump }} G_{\text {pump }}(s)+P_{r e f} G_{r e f}(s)+x K_{\text {rig }}(s) \\
G_{\text {pump }}(s) & =\frac{\tau(\alpha) A}{K\left(\frac{\omega_{n}^{2}}{s^{2}+2 \varepsilon \omega_{n} s+\omega_{n}^{2}}+\frac{V_{0 *}}{K E_{b *}} s\right)} \\
G_{r e f}(s) & =\frac{\tau(\alpha) A}{\left(1+\frac{V_{0 *}}{K E_{b *} \omega_{n}^{2}} s\left(s^{2}+2 \varepsilon \omega_{n} s+\omega_{n}^{2}\right)\right)} \\
K_{\text {rig }}(s) & =\frac{-\tau(\alpha) A^{2}}{K\left(\frac{\omega_{n}^{2}}{s\left(s^{2}+2 \varepsilon \omega_{n} s+\omega_{n}^{2}\right)}+\frac{V_{0 *}}{K E_{b *}}\right)}
\end{aligned}
$$

Some further considerations should be performed from equation (15):

- $G_{\text {pump }}(s): Q_{\text {pump }}$ introduces a disturbance whose influence is rejected by the pressure control loop of the relief valve. In fact, higher valve gain $K$ decreases the module of $G_{\text {pump }}(s)$. It should also be noticed that $Q_{\text {pump }}$ is almost constant since it is produced by a fixed displacement pump, moved by an induction motor directly fed with the standard triphase current at European industrial frequency $(380 \mathrm{~V}, 50 \mathrm{~Hz})$. As a consequence, large pressure fluctuation of the plant pressure produces negligible variations in $Q_{\text {pump }}$.

- $G_{r e f}(s)$ : it is possible to calculate a root locus of $G_{r e f}(s)$ parametrized with respect to valve gain $K$ as visible in Figure 22. For high values of $K$, the system becomes instable.

- $K_{\text {rig }}(s)$ : this transfer function represents the coupling term with the tested system. Thus, to increase the robustness without penalizing too much the gain $K, K_{\text {rig }}(s)$ has to be carefully shaped. For position disturbances with frequencies far higher than the frequency of valve $\omega_{n}, K_{\text {rig }}(s)$ is approximated by equation (16)

$$
s \gg \omega_{n} \Rightarrow K_{r i g}(s) \approx \frac{-\tau(\alpha) A^{2} E_{b *}}{V_{0 *}}
$$

From equation (16), it should be deduced that by moderately increasing the compressibility term $V_{0^{*}} / E_{b^{*}}$, it is possible to reduce the value of $K_{\text {rig }}(s)$ without compromising too much the bandwidth of the pressure controller which should be calculated from the expression of $G_{r e f}(s)$.

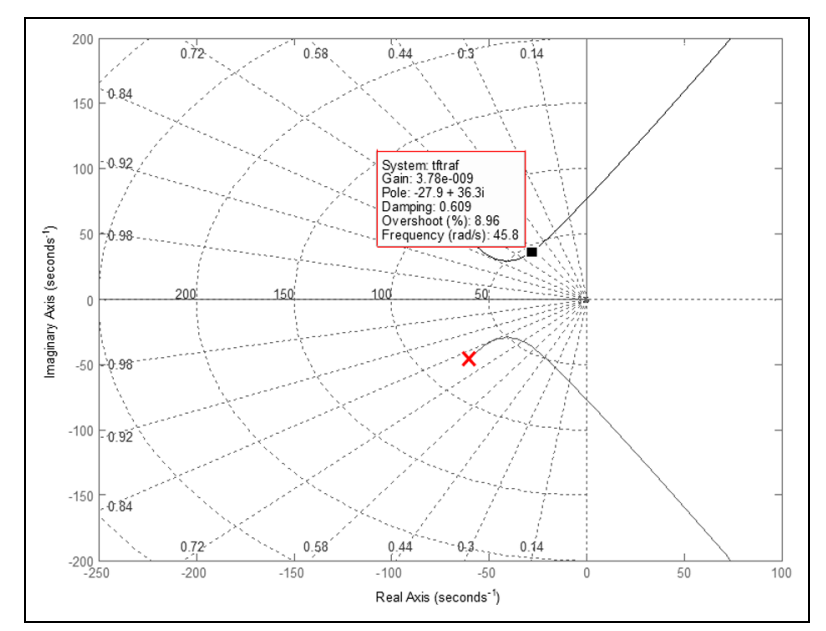

Figure 22. Root locus of $G_{\text {ref }}(s)$.

As a consequence, neglecting the effect of $K_{\text {rig }}(s)$ and $G_{\text {pump }}(s)$, the response of the rig in terms of simulated torque can be approximated by equation (17)

$$
M=G_{r e f} P_{r e f}=\frac{M_{r e f}}{\left(1+\frac{V_{0 *}}{K E_{b \star} \omega_{n}^{2}} s\left(s^{2}+2 \varepsilon \omega_{n} s+\omega_{n}^{2}\right)\right)}
$$

The control signal $P_{\text {stat }}$ is calculated according to equation (11), so the rig starting from an initial value of torque $M(M(0))$ should converge to $M_{r e f}$ according to a time transient described by equation (18) where $\lambda_{1}$, $\lambda_{2}$, and $\lambda_{3}$ are the roots of equation (17), whose behavior with respect to the inner pressure loop $K$ of the valve is represented in Figure 22

$$
\begin{aligned}
M(t) & =a_{1} e^{\lambda_{1} t}+a_{2} e^{\lambda_{2} t}+a_{3} e^{\lambda_{3} t} \\
a_{1} & =\frac{\ddot{M}(0)-\dot{M}(0)\left(\lambda_{2}+\lambda_{3}\right)+\lambda_{2} \lambda_{3}\left(M_{r e f}-M(0)\right)}{\left(\lambda_{1}-\lambda_{2}\right)\left(\lambda_{1}-\lambda_{3}\right)} \\
a_{2} & =\frac{\ddot{M}(0)-\dot{M}(0)\left(\lambda_{1}+\lambda_{3}\right)+\lambda_{1} \lambda_{3}\left(M_{r e f}-M(0)\right)}{\left(\lambda_{2}-\lambda_{1}\right)\left(\lambda_{2}-\lambda_{3}\right)} \\
a_{3} & =\frac{\ddot{M}(0)-\dot{M}(0)\left(\lambda_{2}+\lambda_{1}\right)+\lambda_{1} \lambda_{2}\left(M_{r e f}-M(0)\right)}{\left(\lambda_{3}-\lambda_{2}\right)\left(\lambda_{3}-\lambda_{1}\right)}
\end{aligned}
$$

Therefore, considering an ideal static model of the rig, the control term $P_{\text {stat }}$ is able to assure a steady-state null error through a smoothed transient that can be partially optimized by modifying the compressibility term $V_{0^{*}} / E_{b^{*}}$ and the gain of the inner pressure loop of the servo-valve $K$.

Since the real rig is perturbed by unmodeled dynamics and by disturbances including the interaction with the controlled positioner, the additional reference signal $P_{s l}$ introduces a further correction to reject them and to force the convergence of the system to the desired behavior. In this way, as previously said, the philosophy of the proposed control roughly resembles the sliding mode technique. 
Table 6. Opening and closing times of the tested actuators.

\begin{tabular}{|c|c|c|c|c|c|c|}
\hline \multirow{2}{*}{$\begin{array}{l}\text { Actuator } \\
\text { Air pressure (bar) }\end{array}$} & \multirow{2}{*}{$\begin{array}{l}\text { Scotch yoke } \\
5\end{array}$} & \multicolumn{5}{|c|}{ Pulley and cable innovative actuator } \\
\hline & & 5 & 5.5 & 6 & 6.5 & \\
\hline Torque $(\mathrm{Nm})$ & 1200 & 1200 & Simulated valve load & 1200 & 600 & 1200 \\
\hline$t_{d o}(\mathrm{~s})$ & 2.75 & 1.5 & 1.4 & 1.1 & I & 1.1 \\
\hline$t_{\text {ro }}(\mathrm{s})$ & 18.3 & 13.1 & 15.1 & 13.8 & 12.3 & 17.2 \\
\hline$t_{\text {sso }}(\mathrm{s})$ & 19.9 & 14.4 & 16.8 & 15.4 & 13.6 & 18.9 \\
\hline$t_{o}=\left(t_{r o}-t_{d o}\right) / 3(\mathrm{~s})$ & 5.2 & 3.9 & 4.6 & 4.2 & 3.7 & 5.4 \\
\hline$t_{d c}(\mathrm{~s})$ & 1.6 & 2.6 & 3.8 & 3 & 1.6 & 2.9 \\
\hline$t_{r c}(\mathrm{~s})$ & 6.4 & 7.8 & 9.9 & 10.2 & 8.3 & 9 \\
\hline$t_{s s c}(s)$ & 6.9 & 10.2 & 11.3 & 11.5 & 8.3 & 11.2 \\
\hline$t_{c}=\left(t_{r c}-t_{d c}\right) / 3(\mathrm{~s})$ & 1.6 & 1.7 & 2 & 2.4 & 2.2 & 2 \\
\hline$t_{s s o}+t_{s s c}(s)$ & 26.8 & 24.2 & 28.1 & 26.9 & 21.9 & 30.1 \\
\hline
\end{tabular}

$P_{s l}$ is generated using the saturated high-gain PI controller to reduce chatter troubles which are typically associated with the usage of a pure "bang-bang" controller. In particular, the integral term is useful to compensate constant or low-frequency disturbances such as the one due to $Q_{\text {pump }}$ which is quite low but not completely negligible.

\section{Simulated load tests: experimental results}

Both reference scotch yoke actuator and the innovative one have been tested on the rig in order to verify their dynamical response during the opening and closing transients. Tests are performed considering different loading conditions (constant load or simulated load of the valve) and different pneumatic pressures. In particular, the opening and closing times of the valve are measured in terms of the following parameters:

- Time delay between the application of the step command and the start of the opening $t_{d o}$ or closing motion $t_{d c}$;

- Time needed to reach the $95 \%$ of the final value in the opening $t_{r o}$ or closing $t_{r c}$ phase;

- Time needed to reach the steady-state condition with a negligible residual oscillations or errors (less than $2 \%$ ).

Some of these results are shown in Table 6. It should be noticed that the total time needed to perform a complete opening and closing cycle $\left(t_{s s o}+t_{s s c}\right)$ is almost the same for both the scotch yoke and the innovative actuator. However, for the innovative actuator, there is a lower difference between the opening and closing times. This a quite interesting feature, since a more symmetric behavior of the innovative actuator involves a higher linearity of response. In addition, the value of total cycle time $\left(t_{s s o}+t_{s s c}\right)$ is not very sensitive against loading conditions and pneumatic pressure. This behavior can be easily explained considering that the advance speed of the actuator is constrained by the maximum flow that can be managed by the positioner. It should also be considered that an increase in the

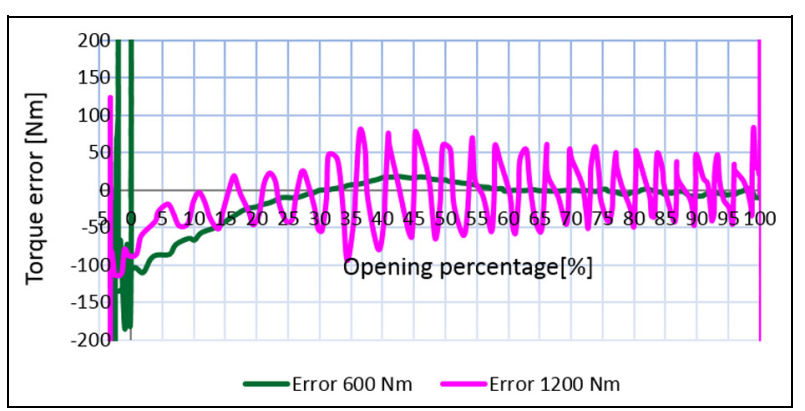

Figure 23. Error on the simulated torque of the rig considering a constant reference value of 600 and $1200 \mathrm{~N} \mathrm{~m}$ and a feeding pressure of the pulley actuator of 6.5 bar.

pneumatic pressure causes a reduction in the opening times, which is compensated by the corresponding increase in the discharge times.

During the tests, the error on the simulated torque is limited to about $50-100 \mathrm{~N} \mathrm{~m}$. This is a satisfying performance of the test rig since the maximum torque that can be delivered by the rig actuator and measured by the chosen load cell is about $10,000 \mathrm{~N} \mathrm{~m}$. Consequently, the relative error on torque simulated by the rig is less than $1 \%$ of the maximum range.

In Figure 23, the error between the reference load that has to be simulated on the rig and the corresponding feedback/measurement is represented. In particular, the results are referred to the innovative pulley actuator during an opening maneuver feed with a pressure of 6.5 bar; the loads that have to be simulated by the rig are constant and, respectively, equal to 600 and $1200 \mathrm{~N} \mathrm{~m}$. It is interesting to notice that lower errors are measured with a lower simulated torque. Apparently, the behavior is difficult to be explained since the mean speed of the actuator is higher with lower loads. However, looking at actuator response visible in Figures 24 and 25, it should be noticed that the pressure torque oscillations in tests with a simulated load of $1200 \mathrm{~N} \mathrm{~m}$ are associated with small motion irregularities and vibrations that are more difficult to be compensated by the rig torque regulator. In particular, the oscillations are deliberately caused by imposing a 


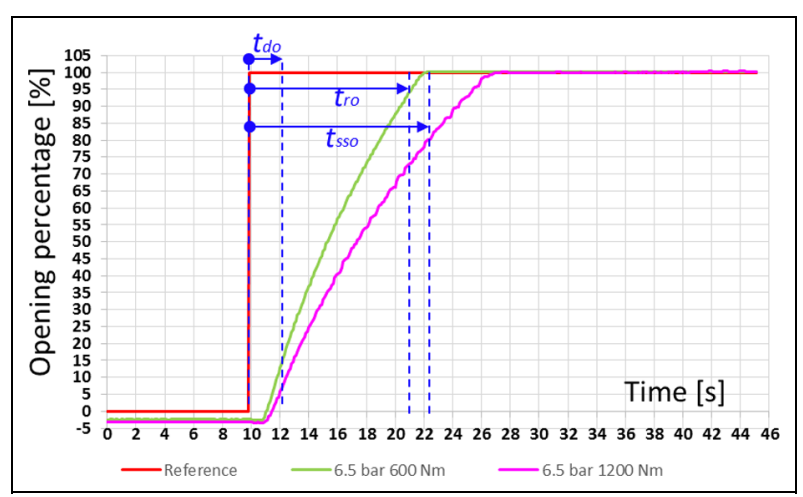

Figure 24. Measured position of the pulley actuator with a constant pressure of 6.5 bar and a constant simulated load of about 600 or $1200 \mathrm{~N} \mathrm{~m}$.

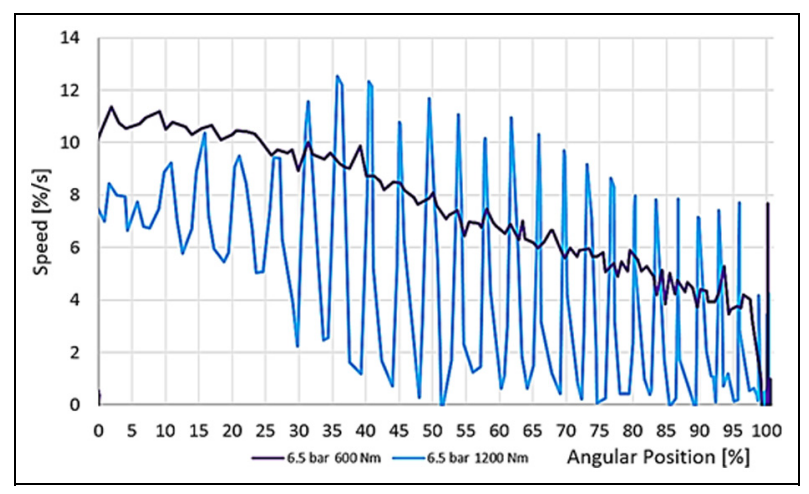

Figure 25. Speed of the pulley actuator with a constant pressure of 6.5 bar and a constant simulated load of about 600 or $1200 \mathrm{Nm}$.

critical working condition for the positioner: the simulated load is near to the maximum load that can be exerted by the actuator and the internal pneumatic regulator of the positioner is calibrated with standard factory settings that are sub-optimal for the proposed actuator. Thus, even when these high-frequency disturbances occur, the rig controller exhibits a stable and damped behavior. More generally, during a simulated load test, visible in Figure 26, with a proper calibration of the pneumatic regulator of the positioner, performances in terms of simulated torque are quite good.

\section{Reliability tests: experimental results}

The same test rig has been used to perform reliability tests in which the actuator is subjected to repetitive simulated load tests. In this preliminary phase of the project, the actuator has been tested with a sequence of 1000 load cycles.

The actuator has successfully completed this preliminary testing campaign; no failing or damaged components have been detected after performing the tests.

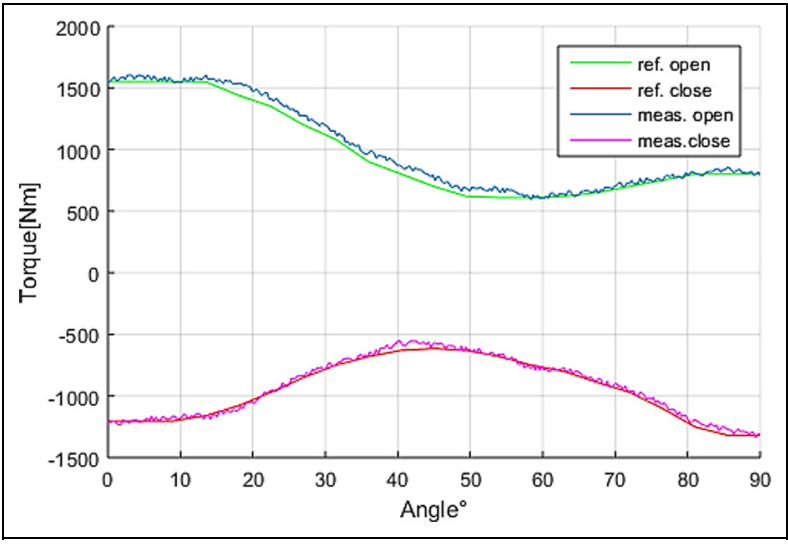

Figure 26. Example of results during a simulated load test (7 bar).

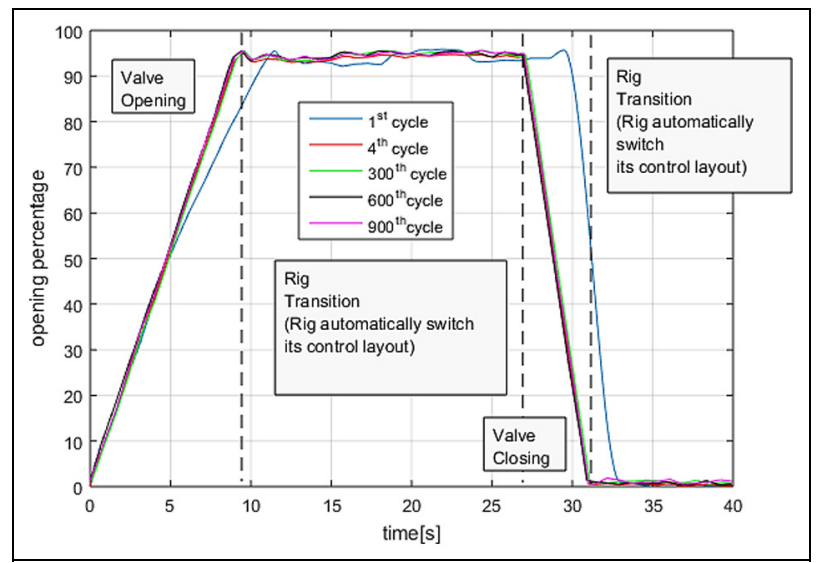

Figure 27. Repeatability of reliability tests: comparison of the response during a reliability test.

In order to verify the suitability of the rig for this kind of tests, the authors have verified the repeatability of the response of both rig and actuators.

In Figure 27, the behavior of the 1st, 4th, 300th, 600th, and 900th load cycles performed on the rig is shown. Only the response corresponding to the first cycle is a bit different with respect to the other ones because of the initialization of both rig and positioner systems. After a transient corresponding to two to three cycles, the difference between each simulated load cycle is almost negligible.

\section{Conclusion and future developments}

In this work, the design of an innovative actuator for quarter turn valve has been presented. In order to identify the response of the proposed actuator, a dedicated test rig has been designed. First, the experimental results are encouraging; the proposed actuator exhibits a higher efficiency with respect to the conventional one. In addition, in terms of response linearity, the proposed actuator seems to be superior to the conventional one. The reduced encumbrances and mechanical simplicity of the proposed solution make it feasible. 


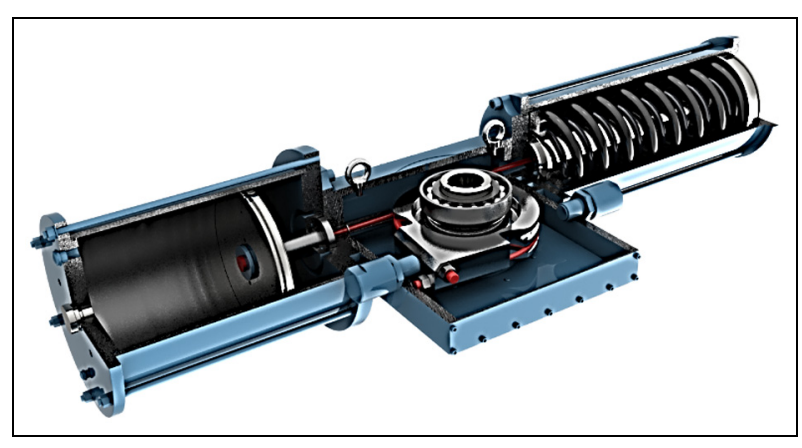

Figure 28. The new actuator, an image of the aligned version from ABV Velan Technical Documentation (November 20I5).

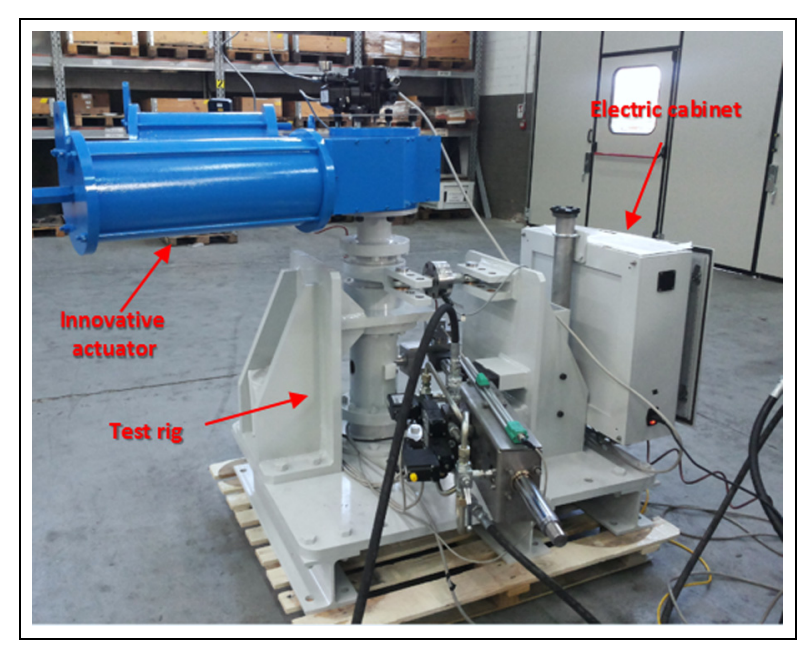

Figure 29. Final layout of the test rig and innovative actuator (March 20I5).

The innovative actuator has been patented ${ }^{19}$ to protect the development of a new series of Velan Products.

Several improvements, in order to further reduce actuator encumbrances and increase efficiency, have been investigated producing design refinements that have been tested on the proposed test rig.

In particular, in Figure 28, an image of the first industrial version of a new actuator is shown: it is an optimized version of the aligned layout of Figure 4(b) also visible in Figure 8 and is probably the object of further publications and research activities.

Depending on commercial feedback, actuators with different sizes (different exerted torques) and layouts (different values of $\beta$ angle such as the first prototype shown in Figure 29) will be probably released.

Consequently, the design of the innovative test rig, which proved to be an ideal tool for testing and identification of this kind of actuators, is an important product of this research activity.

\section{Acknowledgements}

The authors wish to thank engineering students of the University of Florence, such as Giuseppe Occhipinti and Andrea Pulcinelli, for their contribution and for their curious and enthusiastic approach. In addition, the authors wish to remember gratefully all the people of Velan ABV S.p.A., and in particular Fabio Lapini and Michele Graziani, who have contributed to this work with their experience and competence.

\section{Declaration of conflicting interests}

The author(s) declared no potential conflicts of interest with respect to the research, authorship, and/or publication of this article.

\section{Funding}

The author(s) disclosed receipt of the following financial support for the research, authorship, and/or publication of this article: This work was financed as a part of the project High Efficiency Valves (CUP: D55C12 009530007) financed by the program POR CRO FESR of Regione Toscana (European Funds for Regional Industrial $R \& D$ projects).

\section{References}

1. Zaytran I. Rotary actuator. Patent 0127080 B1, USA, 1988.

2. Servovalve S.p.A. Single-acting spring-return hydraulic actuator, for the reciprocating angular movement of a control shaft. Patent EP2216565A1, IT, 2010.

3. Migliori L. Rack and pinion pneumatic actuator with counter-pressure control and damping device. Patent EP0556613A1, IT, 1993.

4. Kermode D. Torque generating actuator. Patent 150040, GB, 1978.

5. Graham CH. Rotary actuator device. Patent 3267816, USA, 1966.

6. Patterson AW. Rotary hydraulic cylinder. Patent 20060162548 A1, USA, 2005.

7. Jaffe DL. Hydraulic rotatory actuator capable of taking high bending moments. Patent 3276332, USA, 1963.

8. V.R.L.S.p.A. Rotary vane hydraulic actuator. Patent 0248986B1, DE FR GB IT, 1992.

9. Devaud G and Rembliere JM. Vane-type rotary hydraulic actuator device intended for driving an aircraft control surface. Patent 4825754, USA, 1989.

10. Morgan DA. Rotary actuator valve closure apparatus. Patent 5975106, USA, 1997.

11. Huska P. Rotary fluid displacement device. Patent 3246580, USA, 1966.

12. D. Technologies S.p.A. Rotary actuator, in particular for a variable valve timing and/or variable valve actuating mechanism. Patent WO03069134A1, USA, 2003.

13. Terp LS. Electropneumatic rotary actuator having proportional fluid valving. Patent 4903578, USA, 1988.

14. Sciavicco L and Siciliano B. Modelling and control of robot manipulators. New York: McGraw-Hill, 2000.

15. Ham RV, Sugar TG, Vanderborght B, et al. Compliant actuator design. IEEE Robot Autom Mag 2009; 16: 81-94.

16. Fiorio L, Parmiggiani A, Berret B, et al. pnrVSA: human-like actuator with non-linear springs in agonistantagonist configuration. In: Proceedings of 12th IEEE$R A S$ international conference on humanoid robots 
(humanoids), Osaka, Japan, 29 November-1 December 2012, pp.502-507. New York: IEEE.

17. Bicchi A and Tonietti G. Fast and soft arm tactics: dealing with the safety-performance tradeoff in robot arms design and control. IEEE Robot Autom Mag 2004; 11(2): 22-33.

18. Iida F, Rummel $\mathbf{J}$ and Seyfarth A. Bipedal walking and running with compliant legs. In: Proceedings of IEEE international conference on robotics and automation, Roma, 10-14 April 2007, pp.3970-3975. New York: IEEE.

19. Allotta B, Papi M, Pugi L, et al. Experimental campaign on a servo-actuated pantograph. In: Proceedings of IEEE/ASME international conference on advanced intelligent mechatronics (AIM), Como, 8-12 July 2001, vol. 1, pp.237-244. New York: IEEE.

20. Allotta B, Pugi L and Bartolini F. Design and experimental results of an active suspension system for a high-speed pantograph. IEEE/ASME T Mech 2008; 13(5): 548-557.

21. Allotta B, Pugi L, Bartolini F, et al. Comparison of different control approaches aiming at enhancing the comfort of a railway vehicle. In: Proceedings of IEEE/ASME international conference on advanced intelligent mechatronics (AIM), Montreal, ON, Canada, 6-9 July 2010, pp.676-681. New York: IEEE.

22. Alleyne A and Liu R. A simplified approach to force control for electro-hydraulic systems. Control Eng Pract 2000; 8: 1347-1356.

23. Pugi L, Pallini G, Rindi A, et al. An hydraulic test rig for the testing of quarter turn valve actuation systems. In: Proceedings of MESA 2014-10th IEEE/ASME international conference on mechatronic and embedded systems and applications, Senigallia, 10-12 September 2014. New York: IEEE.

24. Young KD, Utkin VI and Ozguner U. A control engineer's guide to sliding mode control. In: Proceedings of IEEE international workshop on variable structure systems, Tokyo, Japan, 5-6 December 1996. New York: IEEE.

25. Atos. Technical documentation available at the valve maker site, http://www.atos.com (accessed 9 March 2015).

26. Thayer W. Transfer functions for Moog servo-valves. Moog technical bulletin 103, January 1965. New York: Moog, Inc.

27. Merritt HE. Hydraulic control systems. New York: Wiley, 1967.

28. Allotta B and Pugi L. Meccatronica: azionamenti elettrici ed oleodinamici. 1st ed. Bologna: Esculapio, 2012.

29. Presciani P, Rinchi $M$ and Pugi L. Banchi per la certificazione del componenti frenanti. Ing Ferrov 2003; 58(3): 285-294.

\section{Appendix I}

\section{Notation}

A actuator area $\left(\mathrm{m}^{2}\right)$

$b \quad$ distance between the revolute joint and

$D \quad$ cylinder axes $(\mathrm{m})$

$E_{b^{*}} \quad$ bulk modulus $(\mathrm{Pa})$

$F \quad$ linear force of the hydraulic cylinder $(\mathrm{N})$

$F_{k} \quad$ spring force $(\mathrm{N})$

\section{K}

$K_{\text {pos }}$

$K_{\text {rig }}$

l

$l_{p}$

M $M_{B T C}$

$M_{\text {BTO }}$

$M_{\text {feed }}$

$M_{i d}$

$M_{\text {ref }}$

$M_{p}$

$P$

$P_{\text {init }}$

$P_{\text {pos }}$

$P_{\text {ref }}$

$P_{\text {rig }}$

$P_{s l}$

$P_{\text {stat }}$

$P I$

$P I D$

Q

$Q_{\text {pump }}$

$Q_{\text {valve }}$

$r$

$r_{p}$

$s$

$v$

$V_{0 *}$

$V_{a c c}$

$V_{\text {init }}$

$x$

$x_{a}$

$x_{p}$

$x_{0}$ pneumatic actuator force $(\mathrm{N})$

reaction force on the revolute joint $(\mathrm{N})$

reaction force of the simulated valve $(\mathrm{N})$

reaction force of the actuator (internal

constraint) $(\mathrm{N})$

transfer function of the positioner

controller $(-)$

transfer function of the pump (-)

transfer function between pressure

command and exerted torque (-)

transfer function of the rig controller (-)

stiffness of the spring pack $(\mathrm{N} / \mathrm{m})$

equivalent stiffness of the spring pack

$(\mathrm{N} / \mathrm{m})$

proportional gain (-)

equivalent stiffness of the positioner

$(\mathrm{N} / \mathrm{m})$

equivalent stiffness of the $\operatorname{rig}(\mathrm{N} / \mathrm{m})$

actual piston run (m)

total length of the piston run (m)

exerted torque $(\mathrm{Nm})$

break to close torque $(\mathrm{Nm})$

break to open torque $(\mathrm{N} \mathrm{m})$

measured torque $(\mathrm{N} \mathrm{m})$

exerted torque in ideal conditions $(\mathrm{N} \mathrm{m})$

reference desired torque $(\mathrm{Nm})$

torque of the hydraulic cylinder $(\mathrm{N} \mathrm{m})$

pressure inside the actuator (barG)

initial pressure (barG)

transfer function of the positioner

actuator $(-)$

reference command pressure for the relief

valve (barG)

transfer function of the rig actuator (-)

closed-loop contribution of the pressure

command (barG)

static contribution of the pressure

command (barG)

proportional-integral regulator (-)

proportional-integral-derivative regulator

$(-)$

volumetric flow rate $\left(\mathrm{m}^{3} / \mathrm{s}\right)$

volumetric flow rate of the pump $\left(\mathrm{m}^{3} / \mathrm{s}\right)$

volumetric flow rate of the servo-relief

valve $\left(\mathrm{m}^{3} / \mathrm{s}\right)$

radius of the pulley $(\mathrm{m})$

crank radius of the rig $(\mathrm{m})$

Laplace variable (-)

linear speed of the actuator $(\mathrm{m} / \mathrm{s})$

reference volume $\left(\mathrm{m}^{3}\right)$

volume of the pneumatic accumulator

$\left(\mathrm{m}^{3}\right)$

initial volume $\left(\mathrm{m}^{3}\right)$

spring position $(\mathrm{m})$

longitudinal arm coordinate $(\mathrm{m})$

longitudinal distance between cylinder

pivot and rig rotation axis $(\mathrm{m})$

spring preload (m) 


\begin{tabular}{|c|c|c|}
\hline$y_{a}$ & lateral arm coordinate $(\mathrm{m})$ & $\eta_{\text {prism }}$ \\
\hline$y_{c}$ & $\begin{array}{l}\text { lateral distance between cylinder pivot } \\
\text { and rig rotation }(\mathrm{m})\end{array}$ & $\eta_{\text {rot }}$ \\
\hline$\alpha$ & scaled angular position of the valve $\left(^{\circ}\right)$ & $\mu$ \\
\hline$\alpha_{r e f}$ & $\begin{array}{l}\text { scaled angular position of the valve } \\
\text { (reference value) }\left(^{\circ}\right)\end{array}$ & $\rho$ \\
\hline$\beta$ & characteristic angle of the actuators $\left(^{\circ}\right)$ & \\
\hline$\gamma$ & $\begin{array}{l}\text { coefficient of polytropic transformations } \\
(-)\end{array}$ & $\begin{array}{l}\tau \\
\tau_{\text {end-run }}\end{array}$ \\
\hline$\delta$ & $\begin{array}{l}\text { radius of the friction circle for the rope } \\
\text { bearings }(\mathrm{m})\end{array}$ & \\
\hline$\varepsilon$ & damping coefficient $(-)$ & $\omega_{n}$ \\
\hline$\eta$ & global efficiency $(-)$ & \\
\hline
\end{tabular}

efficiency of the prismatic joint (-)

efficiency of the revolute joint $(-)$

valve angular position $\left({ }^{\circ}\right)$

friction coefficient $(-)$

radius of the friction circle for the pulley bearings $(\mathrm{m})$

global radius of the friction circle $(\mathrm{m})$

transmission ratio $(-)$

end-run transmission ratio $(-)$

friction angle $\left(^{\circ}\right)$

angular speed ( $\mathrm{rad} / \mathrm{s})$

natural pulsation ( $\mathrm{rad} / \mathrm{s})$ 